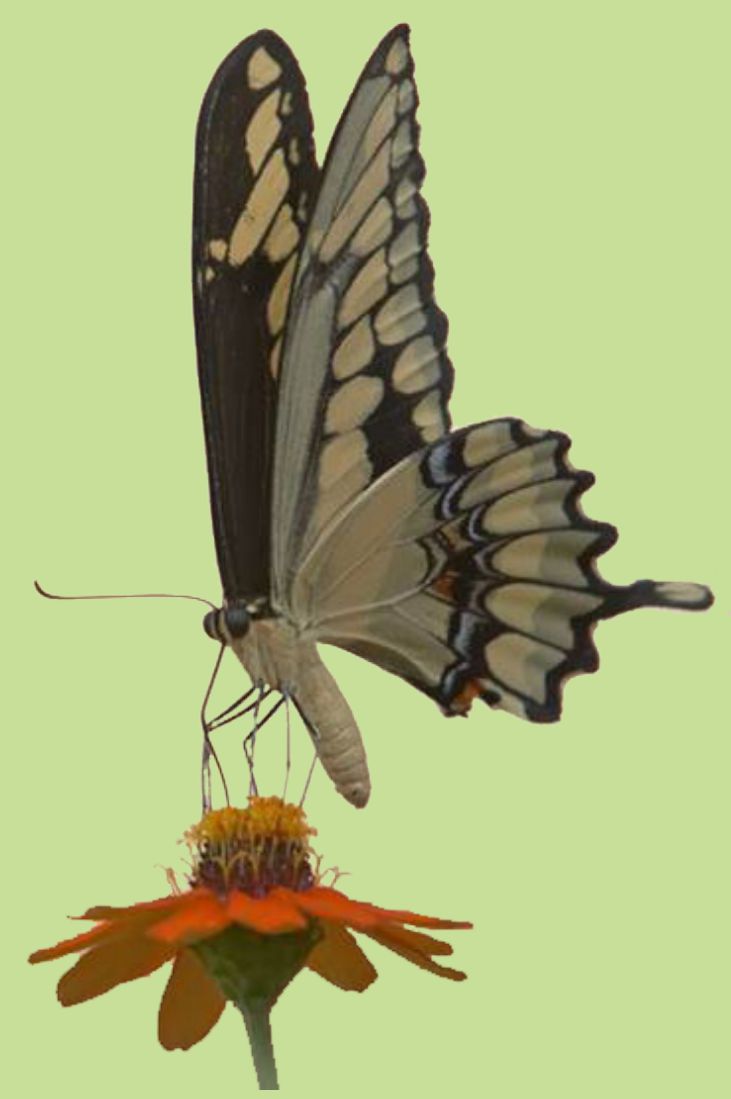

Weaving the SDGs

A reflection on quadrangles

and embodied practices

Verena WINIWARTER (Ed.)

KIOES Opinions 11 (2021)

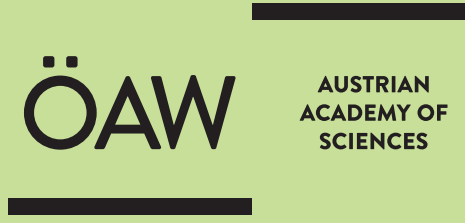





\section{Weaving the SDGs A reflection on quadrangles and embodied practices}


KIOES Opinions 11 (2021): 1-39.

doi: 10.1553/KIOESOP_0011

Imprint:

KIOES Opinions are published by the Commission for Interdisciplinary Ecological Studies (KIOES) of the Austrian Academy of Sciences (OeAW). KIOES publishes current opinions written, initiated or invited by KIOES related to topical subjects on an irregular basis in KIOES Opinions. The target audience includes scientists, policy makers and the public. Opinions expressed in this article are solely those of the author(s), and they do not necessarily reflect in any way those of KIOES or OeAW.

More information about KIOES and download of KIOES Opinions at http://www.oeaw.ac.at/kioes

Managing Editor:

Viktor J. Bruckman

Layout: Karin Windsteig

Cover photo credit: Fotofolia

Images credits: Contribution Charlotte Holzer (p. 13-27)

Fig. 1, 2, 5, 6, 7, 8, 9, 12, 15, 16, 18, 19, 20, 21, 22, 23: Franziska Lipp

Fig. 3, 4, 11, 13, 14, 17: Charlotte Holzer

Fig. 10: Azote Images for Stockholm Resilience Centre, Stockholm University

Editorial office:

Commission for Interdisciplinary Ecological Studies, OeAW, Dr. Ignaz Seipel-Platz 2, 1010 Vienna

E-mail: viktor.bruckman@oeaw.ac.at, +43151581 3200 


\section{Table of Contents}

\section{VERENA WINIWARTER}

Preface

\section{VERENA WINIWARTER}

Weaving the SDGs - a reflection on quadrangles and embodied practices ................................

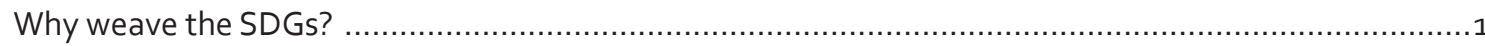

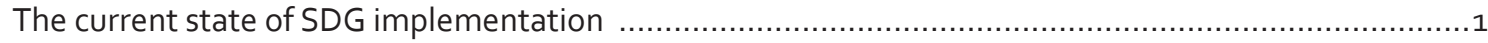

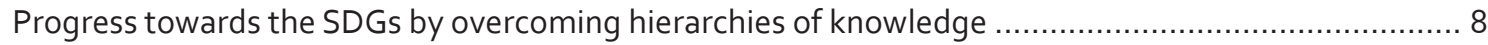

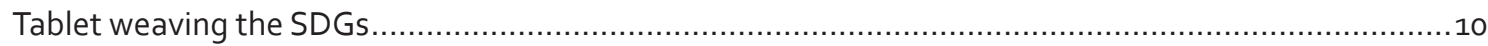

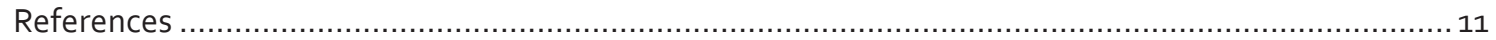

\section{Charlotte Holzer}

Thinking through weaving - An Experimental Approach to the UN Sustainable Development

Goals

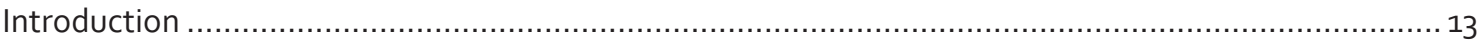

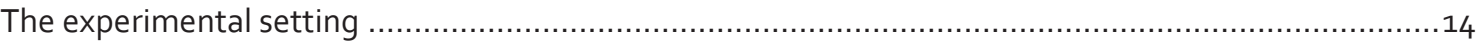

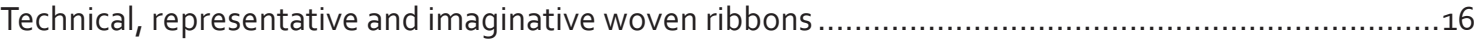

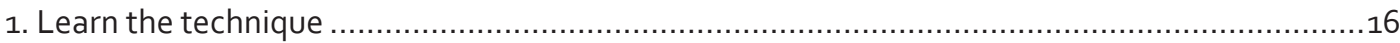

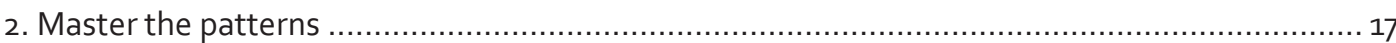

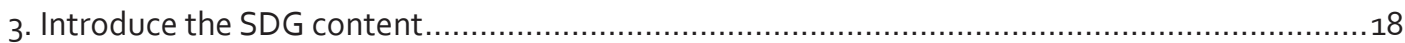

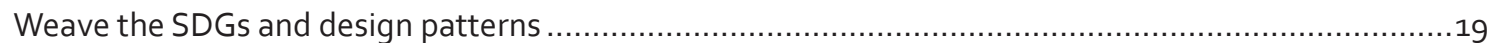

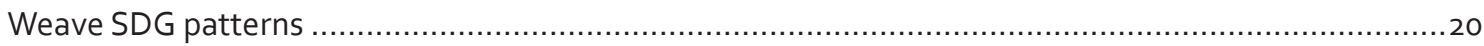

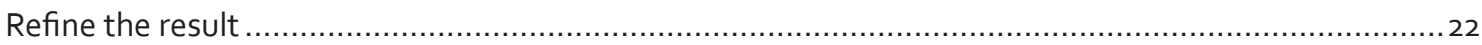

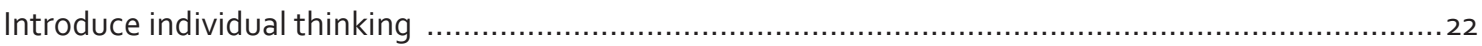

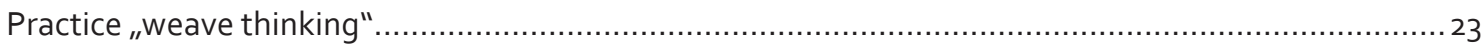

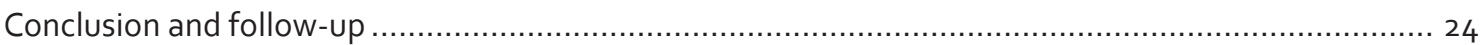

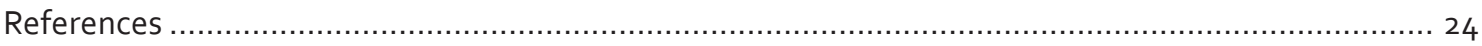

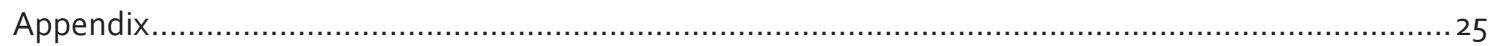

Weaving a new fabric of society. Reflections on the Sustainable Development Goals and

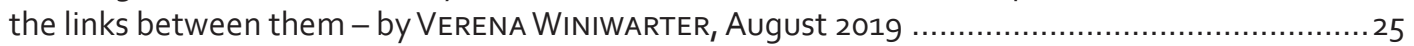

Documentation of reflections and feelings about the first attempts in tablet weaving - by CHARLOTTE HOLZER, August 2019

\section{ELLEN HARLIZIUS-KLÜCK}

Crafting Sustainability: On weaving as mode of (re-)production......................................... 29

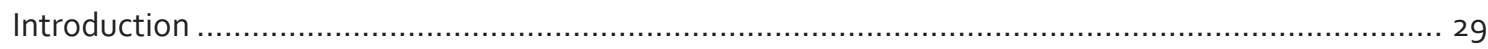

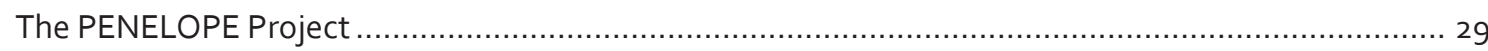

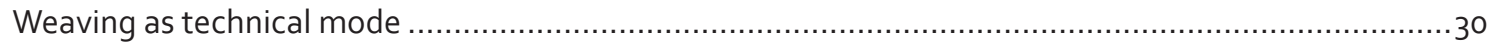

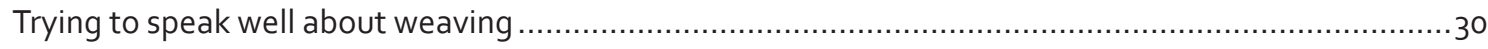

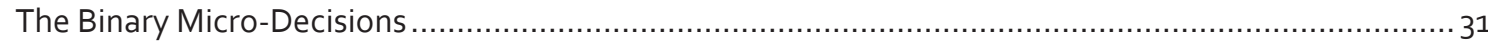

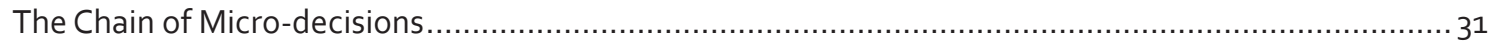

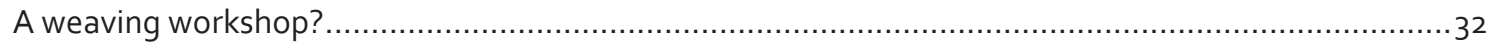




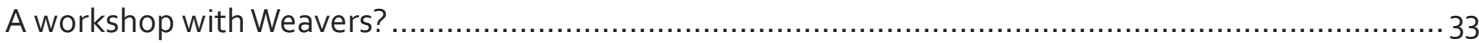

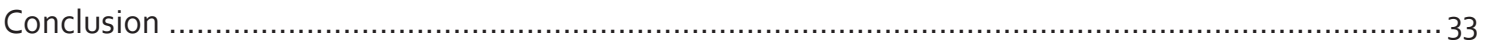

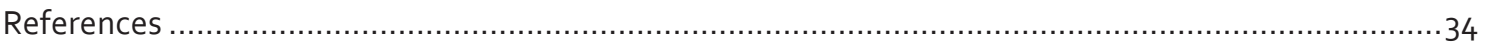

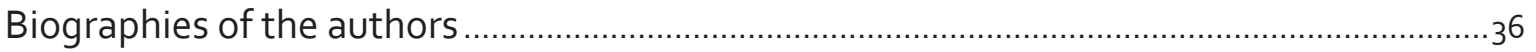




\section{Preface}

\section{VERENA WINIWARTER}

On December $2^{\text {nd }}, 2020$, UN Secretary General Antonio Guterres gave a brief address at Columbia University. It was published in the environmental newsletter "Sonnenseite“ in Germany in a slightly abbreviated form, transcribed from the video and summarized by Udo Simonis. ${ }^{1}$ The poignant speech is an urgent call for action and re-iterates that the Agenda 2030, the Sustainable Development Goals, remain the blueprint for such action: „This is a moment of truth for people and planet alike. COVID and climate change have brought us to a threshold. We cannot go back to the old normal of inequality, injustice and heedless dominion over the Earth. Instead, we must step towards a safer, more sustainable and equitable path. And we have a blueprint for all that: the 2030 Agenda, the Sustainable Development Goals and the Paris Agreement on climate change."

In 2018, three years into the Agenda 2030, the Commission for Interdisciplinary Ecological Studies of the Austrian Academy of Sciences brought together a group of experts to analyse the challenges for implementation of the SDGs in Austria. As Chairperson of the Commission, I also served as one of the authors. The Presidency of the Austrian Academy of Sciences decided that the Academy should use its means to contribute to the implementation of the goals and organized the hitherto largest congress on the SDGs held in this country. The congress was special also for its focus. The issue of making sustainable development possible in a mediatized, and globally connected world dominated by mass and social media was chosen as an under-researched topic to be the main focus of the plenary program. In April 2019, more than 300 people gathered to listen to a cast of international speakers and share their own research and ideas. While the highly interactive congress was not easy to document, a publication resulted that captured at least the keynotes and documented the results from the many working groups ${ }^{2}$. After the congress, many colleagues held high hopes that the gathering would be an important step in mainstreaming the SDGs in Austria.

But the voluntary progress report by the Austrian government, published in 2020, was rather disappointing, cherry-picking rather than encompassing, and focussing on achievements while glossing over challenges ${ }^{3}$. Since 2015, I had had many conversations with colleagues and students about the Agenda 2030. I also taught several university-level courses on the SDGs. Some of my partners shared their frustration, pointing me e.g. to the fact that the SDGs would not address extreme poverty, that the indicators were so vague that practically everything that was already done could be sold as a success with regard to the SDGs.

Guideline documents by the UN are necessarily chimerical, boundary objects between political and expert realms. They are the result of compromises and that quite unavoidably earns them critique. But the SDGs were not just a guideline document. They were widely successful as a graphical marker for anyone who wanted to decorate and thus legitimize their activities as pertaining to the SDGs. The webpages of

\footnotetext{
1 https://www.sonnenseite.com/en/politics/the-state-of-the-planet-is-broken/

2 https://www.oeaw.ac.at/fileadmin/NEWS/2020/PDF/Webversion AiD 18.pdf

3 https://sustainabledevelopment.un.org/content/documents/26512VNR 2020 Austria Report English.pdf
} 
the UN themselves are forerunners in such labelling, which is greatly facilitated by the official graphical representation of the SDGs as a series of brightly colored, unconnected quadrangles.

This representation, I speculated, might well play a role in the apparent failure of the Agenda 2030 to transform society at large. There was so much energy in so many people, so many I had met saw the SDGs as a fantastic opportunity, and yet, it seemed that their efforts ended up in a lot of guidelines, reports, discussion papers, but in little action. What kind of representation could spur a transformative practice? What kind of learning would stakeholders need to be able to put knowledge into practice?

Local and regional transdisciplinary attempts at using the framework to foster desirable developments often fared a better fate than big schemes, or so, was my impression.

Several publications on the networked nature of the goals and targets had shown how connected the agenda was and I had been teaching a networked approach. Thinking about networks made me think of woven fabric. When I came across the work of Ellen Harlizius-Klück, I was fascinated. Weaving could perhaps instil the networked thinking that the goals in their boxes would not yield? I taught myself the basics of tablet weaving in a holiday apartment over the summer. It was taxing, but without the knowledge I acquired by weaving, I could not have co-operated with Ellen or later, Charlotte. Ellen was kind enough to visit me in Vienna, and we discussed my attempts. By then I was dreaming of workshops for decision makers, letting them not only experience the interconnectedness of the goals, and the challenges of the paths towards their implementation, I also had produced objects that could perhaps serve as trinkets, as take-home products of such a workshop. It turned out that my attempts were short-sighted and not true to the essence of what "Weaving the SDGs" actually was about.

Charlotte Holzer, whose reflexive CV is part of this volume, as those of Ellen Harlizius-Klück and myself, transformed herself into a tablet weaver over long months of experimenting. I followed her journey and after several meetings, we presented her work and my thinking, which had greatly benefitted from our exchanges, in March 2020, at the Deutsches Museum, speculating that in the context of SDG-themed exhibitions, weaving might become part of the programs of the museum. The positive feedback energized us, but it would take almost one more year to write up our journey so that others could follow. Each of us is speaking in her own voice, but we have commented extensively on each other's writing. To allow readers a better understanding of the perspective we take, we have written CVs exclusively for this publication. We invite comment and discussion.

The KIOES Opinions are designed for different formats. This issue of the "Opinions" is hopefully more than just a project documentation, although it allows us to thank the Austrian Academy of Sciences for their financial support, which was essential. Thanks are also due to Karin Windsteig and Viktor Bruckman, who create the product from the manuscripts.

We wish our readers an inspiring journey through the text and hope that we could contribute in our special way to the implementation of the Agenda 2030. 


\title{
Weaving the SDGs - a reflection on quadrangles and embodied practices
}

\author{
VERENA WINIWARTER
}

\section{Why weave the SDGs?}

The following introduction to the report on an experimental project financed by the Austrian Academy of Sciences and carried out in co-operation with Deutsches Museum, Munich, starts with observations on the current state of implementation of the Sustainable Development Goals worldwide and in Austria. It identifies the images used to communicate the SDGs as one overlooked lever for the transformation the SDGs seek to achieve. Finally, it discusses embodied practices as a way forward. The final section introduces a concrete craft practice, that of tablet weaving to fill the metaphor of „weaving a new tapestry for society“ with life.

\section{The current state of SDG implementation}

In its interdisciplinary report from 2018, the Commission for Interdisciplinary Ecological Studies of the Austrian Academy of Sciences gave an overview of the UN Agenda 2030, better known as Sustainable Development Goals (SDGs), and their interdependences (Winiwarter 2018). The report also discussed the situation in Austria, calling for more action. Since then, the SDG's international Independent Panel of Scientists, among them Austrian demographer Wolfgang Lutz, published their first report on progress in implementing the SDGs. Its title is „The Future is Now" (Independent Group of Scientists appointed by the Secretary-General 2019). Its executive summary uses remarkably strong wording and leaves no doubt about the lack of implementation and progress (emphasis added):

„However, despite the initial efforts, the world is not on track for achieving most of the 169 targets that comprise the Goals. The limited success in progress towards the Goals raises strong concerns and sounds the alarm for the international community. Much more needs to happen - and quickly - to bring about the transformative changes that are required: impeding policies should urgently be reversed or modified, and recent advances that holistically promote the Goals should be scaled up in an accelerated fashion.

Adding to the concern is the fact that recent trends along several dimensions with cross-cutting impacts across the entire 2030 Agenda are not even moving in the right direction. Four in particular fall into that category: rising inequalities, climate change, biodiversity loss and increasing amounts of waste from human activity that are overwhelming capacities to process them. Critically, recent analysis suggests that some of those negative trends presage a move towards the crossing of negative tipping points, which would lead to dramatic changes in the conditions of the Earth system in ways that are irreversible on time scales meaningful for society. Recent assessments show that, under current trends, the world's social and natural biophysical systems cannot support the aspirations for universal human well-being embedded in the Sustainable Development Goals. 
Just over 10 years remain to achieve the 2030 Agenda, but no country is yet convincingly able to meet a set of basic human needs at a globally sustainable level of resource use. All are distant to varying degrees from the overarching target of balancing human wellbeing with a healthy environment. Each country must respond to its own conditions and priorities, while breaking away from current practices of growing first and cleaning up later. The universal transformation towards sustainable development in the next decade depends on the simultaneous achievement of country specific innovative pathways."

After this rather dire assessment, the report continues: „Nevertheless, there is reason for hope. Human well-being need not depend on intensive resource use, nor need it exacerbate or entrench inequalities and deprivations. Scientific knowledge allows for the identification of critical pathways that break that pattern, and there are numerous examples from across the world that show that it is possible." (all quotes in Independent Group of Scientists appointed by the Secretary-General 2019, p. XX) Scientific knowledge, the report implies, is the way for- ward. It identifies pathways for breaking the pattern of intensive resource use, inequalities and deprivation. But what kind of scientific knowledge does that, how are patterns broken and what kind of new patterns should and could emerge? The report suggests four levers as entry points for a transformation. They are governance, economy and finance, individual and collective action and finally, science and technology.

Among the many implementation problems that both the ÖAW and the international report identified are (1) indicators to measure meaningfully, (2) avoiding cherry-picking of goals, targets or periods of reporting and (3) supporting practices that make a difference rather than those that are greenwashingfeel-good pseudo-solutions.

Can we learn from the UN? The SDGs have given rise to a specialised practice within UN organisations, showing each of the goal quadrangles to which a particular initiative contributes. One such image, taken from UNIDO $^{1}$ is shown in Figure 1, but hundreds of such images exist.
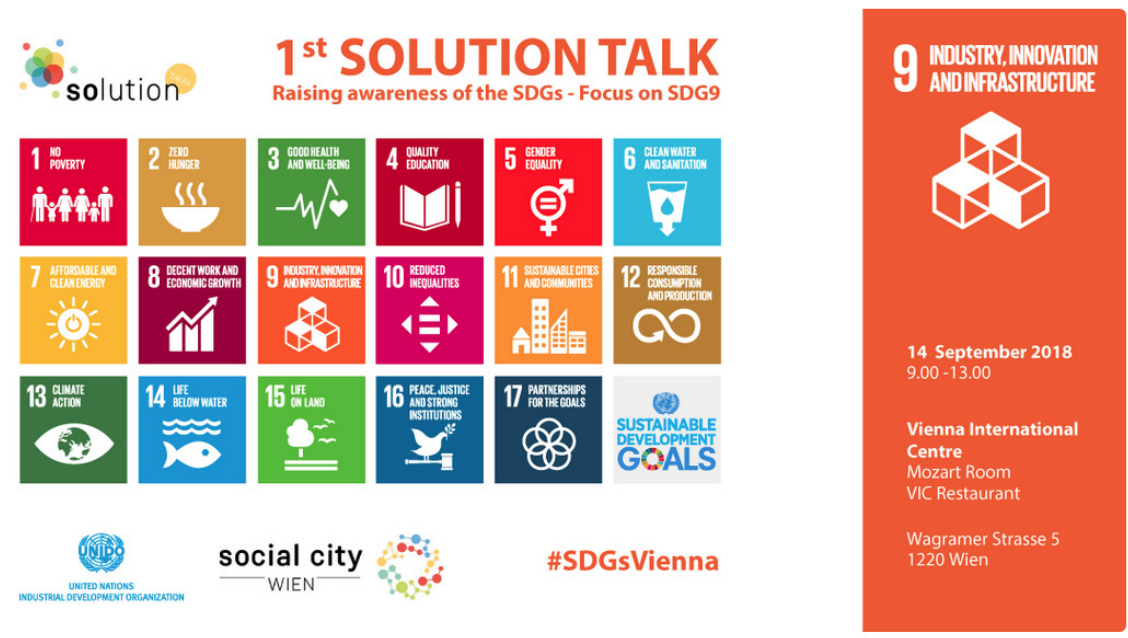

\section{SolutionTalks - Raising awareness of the SDGs in Vienna}

UNIDO supports all 17 SDGs, but puts a strong emphasis on SDG9, which focuses on building resilient infrastructure, promoting inclusive and sustainable industrialization and fostering innovation. These are critical for developing countries, and equally

Figure 1: screenshot from https://www.unido.org/viennas-sdgs-solutiontalks, accessed on Sept. 15, 2020.

$1 \quad$ https://www.unido.org/viennas-sdgs-solutiontalks 
The SDGs have also led to specialised reports detailing how little progress has been made, one of the most recent ones by the OECD (OECD 2020). Their executive summary (p. 19) reads: „The transformative nature of the 2030 Agenda provides a key opportunity for national, regional and local governments to promote a new sustainable development paradigm." This uplifting assessment on the potential is followed by a rather devastating report. After five years, that is, one-third of the time to achieve the goals and with only ten years to go, „At least $80 \%$ of regions from OECD countries have not achieved the suggested end values for 2030 in any of the 17 goals. Not a single region in the OECD has achieved the suggested end values for SDG 13 on „Climate Action“ and SDG 5 on „Gender Equality.“ (p. 21). This report, of particular importance due to still growing urbanisation, concludes with a "Checklist for Public Action“ to facilitate the uptake and implementation of the SDGs. It is summarised here without identifying each verbatim quote. All text is taken from page 21 of the report. Key recommendations are to use the SDGs to define and shape local and regional development visions, strategies, plans, and re-orient existing ones. Clean forms of urban mobility, affordable housing, gender equality, access to green spaces, balanced urban development, clean water and sanitation, air quality, solid waste management, territorial inequalities, or service delivery should be aimed for. Policy priorities, incentives, and objectives should be aligned across national, regional and local governments. Regions and cities should be engaged in the process of Voluntary National Reviews to reflect progress at subnational level and address regional disparities. The OECD hopes that Voluntary Local Reviews would also drive better multi-level governance. The OECD calls for mainstreaming the SDGs in budgeting processes to ensure adequate resources are allocated for the implementation of the Agenda 2030. Governments should allocate financial resources based on the identified place-based policy priorities and key local challenges, and use the SDGs framework as a means to foster integrated multi-sectoral programmes and priorities. Localised indicator systems should be developed to guide policies and actions for better people's lives. In particular, for more comprehensive assessment and policy responses, cities and regions should combine data and indicators at different scales, from those related to administrative boundaries (the unit for political and administrative action) to those related to functional approaches (the economic geography of where people live and work). Finally, the OECD suggests that the SDGs be used as a vehicle to enhance accountability and transparency through engaging all territorial stakeholders, including civil society, citizens, youth, academia and private companies, in the policy-making process. Cities and regions should use a combination of various tools to engage local stakeholders, such as awareness-raising campaigns, networking opportunities, but also de-risking investments in SDG solutions through grants or loans, as well as fiscal incentive for innovative solutions towards sustainability. How all this „should“ can be put into action remains on the level of best practice suggestions in the report. But can one do much better?

Rich countries with good education systems and developed democratic governance structures, with free media and a long history of peace have a far easier road to reaching the SDGs than those under challenging conditions. Austria is a good example for such a country. It could use its privileged position to make progress towards the goals. But the Austrian Progress Report (all national reporting is voluntary!) (Bundeskanzleramt (2020), decided to focus on success stories and remains on a very general level. The assessment of progress towards each goal uses arrows to show if progress is made or not. While the text (emphasis added) allows for some more critical views, the images (a selection can be found in Figure 2) are meant to convince readers that everything is fine: „Greenhouse gas emissions decreased slightly between 2010 and 2014 before increasing by $3.3 \%$ from 2016 to 2017. The main reasons for this included the sharp increase in sales of transport fuel and the increased use of fossil fuels in industrial and energy companies (Environment Agency Austria 2019). According to the latest figures, Austria's greenhouse gas emissions amounted to around 79 million tonnes in 2018. This equates to a fall of $3.8 \%$ or 3.1 million tonnes of $\mathrm{CO}_{2}$ equivalent as compared to 2017. One reason for that was mild weather. At 9.4 tonnes of $\mathrm{CO}_{2}$ equivalent per resident, Austria's greenhouse gas emissions were slightly higher than the EU-28 average of 8.8 tonnes per capita." (p. 91) - Thanks to mild weather, Austrian officials can claim progress where there is little if any. Unfortunately, glossy paper progress reports with relatively little substance are rather the norm than the exception. The case of Austria shows that little progress can be expected if all reporting remains voluntary and unstandardized. 


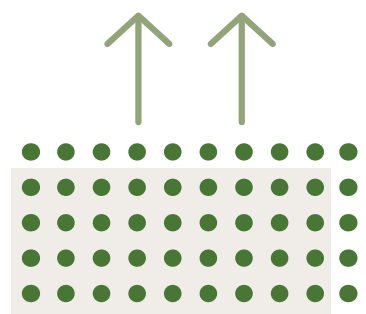

Per capita emissions in Austria were around $8 \%$ higher than

the EU-28 average in 2017.

\begin{tabular}{lll} 
Target & National indicators (selected) & Trend \\
\hline 13.1 & $\begin{array}{l}\text { Deaths attributed to natural disasters } \\
\text { per 100,000 population }\end{array}$ & Heat-related excess mortality \\
\cline { 2 - 3 } & National crisis and disaster management & $\begin{array}{l}\text { Soldiers deployed for disaster relief } \\
\text { operations in Austria }\end{array}$ \\
\hline 13.2 & $\begin{array}{l}\text { Austrian strategy for adaptation to } \\
\text { climate change }\end{array}$ & $\begin{array}{l}\text { Greenhouse gas emissions } \\
\text { Gon-ETS greenhouse gas emissions } \\
\text { (= effort sharing) }\end{array}$ \\
\hline TARGET
\end{tabular}

Figure 2: Two images from Austria's first voluntary national SDG report, from the chapter on SDG 13, Climate Action. (p. 88f). https://sustainabledevelopment.un.org/content/documents/26511VNR 2020 Austria Report English.pdf

So how about the scientific community? The Austrian Academy of Sciences held the biggest Austrian congress to date on the SDGs in 2019, highlighting a lot of great research inspired by the SDGs. Some impressions from it can be found in a publication titled „Global Sustainable Development Goals in a Mediatized World". The main theme of the congress was to discuss how the global mediatization of society changes the opportunities and challenges for implementation (Österreichische Akademie der Wissenschaften 2020). Among the cast of plenary speakers were $\mathrm{Ne}$ bojsa Nakicenovic, who spoke about an international initiative called „The World in 2050 (TWI2050)“. ${ }^{2}$ This initiative is a good example of SDG-related science activities. According to the project's description, TWI2050 was launched by the International Institute for Applied Systems Analysis (IIASA), the Sustainable Development Solutions Network (SDSN), and the Stockholm Resilience Centre (SRC) as a global research initiative in support of a successful implementation of the United Nations' 2030 Agenda. The goal of TWI2050 is to provide the fact-based knowledge to support the policy process and implementation of the SDGs. The group identifies Six Grand Transformations towards the Sustainable Development Goals, depicted in Figure 3 in an updated version including the COVID-19 response. According to the authors of a recent publication, the transformations are conceptualized as „modular building-blocks" of SDG achievement: (1) education, gender and inequality; (2) health, well-being and demography; (3) energy decarbonization and sustainable industry; (4) sustainable food, land, water and oceans; (5) sustainable cities and communities; and (6) digital revolution for sustainable development (Sachs et al. 2019). As is immediately visible, the focus here is on innovation. Innovation, the driving force for the past 200 years of European history and later, world history, is one area on which many stakeholders can agree, as it is the most commonly agreed-upon (or least controversial) driver of success.

Demographer Wolfgang Lutz presented his revolutionary indicator „YoGL“ at another plenary talk at the congress. He suggests switching from a global fixation on economic growth by measuring GDP (Gross Domestic Product) to an indicator for assessing sustainable human wellbeing, „Years of Good Life“ (Lutz et al. 2018). As can be seen in Figure 4, the „Years of Good Life" are calculated by determining years of life above a minimum threshold both in terms of objective well-being dimensions as well as subjective life satisfaction. Maximising YoGL in a population sustainably, that is, without moving a population away from the SDGs, would, so the argument, be the most sensible way forward. Three indicators are used to determine the capable years of life: (1) Being out of absolute poverty (2) being able to read and comprehend a sentence, as assessed through a standardised

2 https://iiasa.ac.at/web/home/research/twi/TWI2050.html 


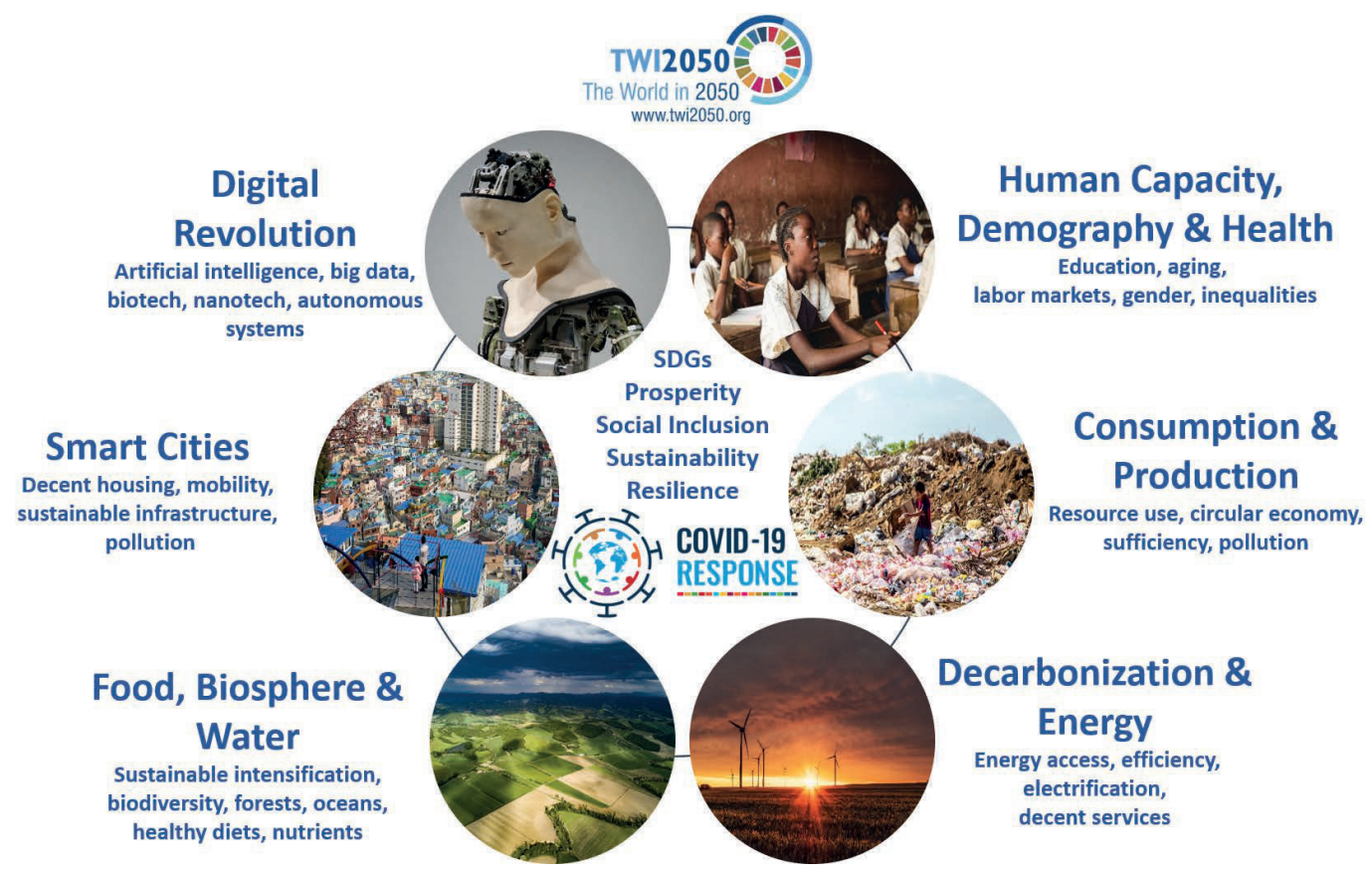

Figure 3: The Six Transformations envisaged by TWI 2050, taken from http://pure.iiasa.ac.at/id/eprint/16533/1/TWI2050web-2.pdf (p. 13), accessed on April 12, 2021.

test of basic literacy and finally, (3) having no severe activity limitation. A ,single item life satisfaction scale" was used to assess the subjective years with positive satisfaction, which are depicted as yellow circle. According to Lutz et al. (2018), YoGL as new summary indicator can be the basis of a sustainability transformation. The big red circle shows the overall years of life which summarise the expected length of life of a person based on the currently observed mortality/ survival rates in the chosen population. The Years of Good Life are a subset of these overall years of life that result from the overlapping area (green area) of the capable years of life (blue circle, defined by three measurable criteria) and years with subjective life satisfaction above a minimal level (yellow area).

These glimpses of the ongoing discussion should not be mistaken as an overview. But, taken together with the above-mentioned report from 2018, they show that the SDGs' announcement in 2015 has initiated a flurry of activities, among them some very interesting scientific attempts and a lot of reporting, unfortunately sometimes on the border of cherry-picked greenwashing. Assessments have shown that the implementation gap has not narrowed over the past five years. As briefly discussed in the preface to this

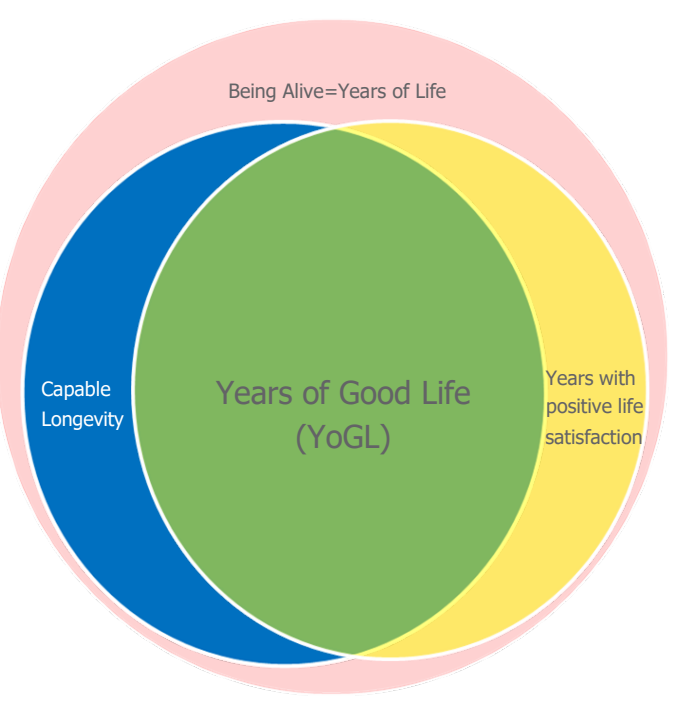

Figure 4: Years of Good Life (YoGL) as a new summary indicator for sustainability transformation. Taken from http://pure.iiasa.ac.at/id/eprint/15402/1/WP-18-007.pdf (p. 8), accessed on Sept. 15, 2020. 
volume, after many conversations and after teaching several university-level courses on the SDGs, I had started wondering which role the official graphical representation of the SDGs might play in the apparent failure to TRANSFORM society at large. Any user of websites dedicated to SDG implementation will have seen forbidden versions of either the „colour wheel" or the icons of the SDGs, despite a 68page guideline on proper use. Figure 5 shows two instances of forbidden uses (UN Department of Global Communications 2018).

The Colour Wheel must not have anything but colours, so reducing the goals to a palette without apparent content, and, while apparently parts of a wheel, lacking connection and a centre. The icons, as shown in Figure 6 from the guidelines, are particularly problematic as they are an orthogonalised set of quadrangles. They are, as Ellen Harlizius-Klück kindly observed, overdetermined by carrying a color, a number, a text and an icon each ${ }^{3}$.

While the guidelines sound very definitive, there is even an UN page on resources for SDG outreach activities that are apparently okay, although would not be allowed according to the guidelines. ${ }^{4}$

Stacks of cubes with the SDGs on were used at several events in Austria. A variety of 3-D-items to promote the SDGs such as cubes are available. ${ }^{5}$ It is rather sobering to see the amount of merchandise produced and sold in promoting the SDGs. These items are not indicating a transformation; rather, their production signals a "more of the same" approach (see Figure 8 for an example).

\section{SDG COLOUR WHEEL DON'TS \\ USAGE LOGO: DON'TS}

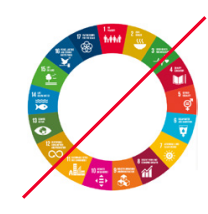

DO NOT place the icons
on the colour wheel

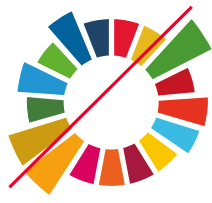

DO NOT reposition/rearrange
elements of the colour wheel

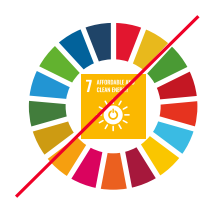

DO NOT place the icon
inside the colour wheel

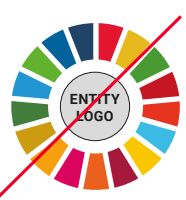

DO NOT place entity's logo
inside the colour wheel

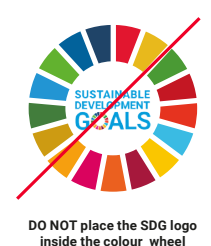

DO NOT place the SDG logo
inside the colour wheel
ICONS

DON'TS

ICON USAGE: DON'TS

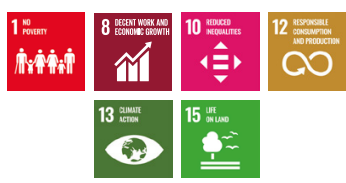

DO NOT mix, match or group select
SDG icons into arbitrary clusters

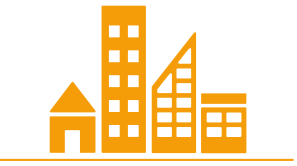

DO NOT use SDG icon graphic

Figure 5: Examples of uses of the SDG Colour Wheel and Icons that are officially forbidden. Compare Figure 1 for an apparently forbidden use from within the UN, accessed on Sept. 15, 2020. (UN Department of Global Communications 2018).

\footnotetext{
3 Personal communication with the author, 2019.

4 https://www.globalgoals.org/resources

5 https://sdgactionshop.org/products/sdg-cubes
} 


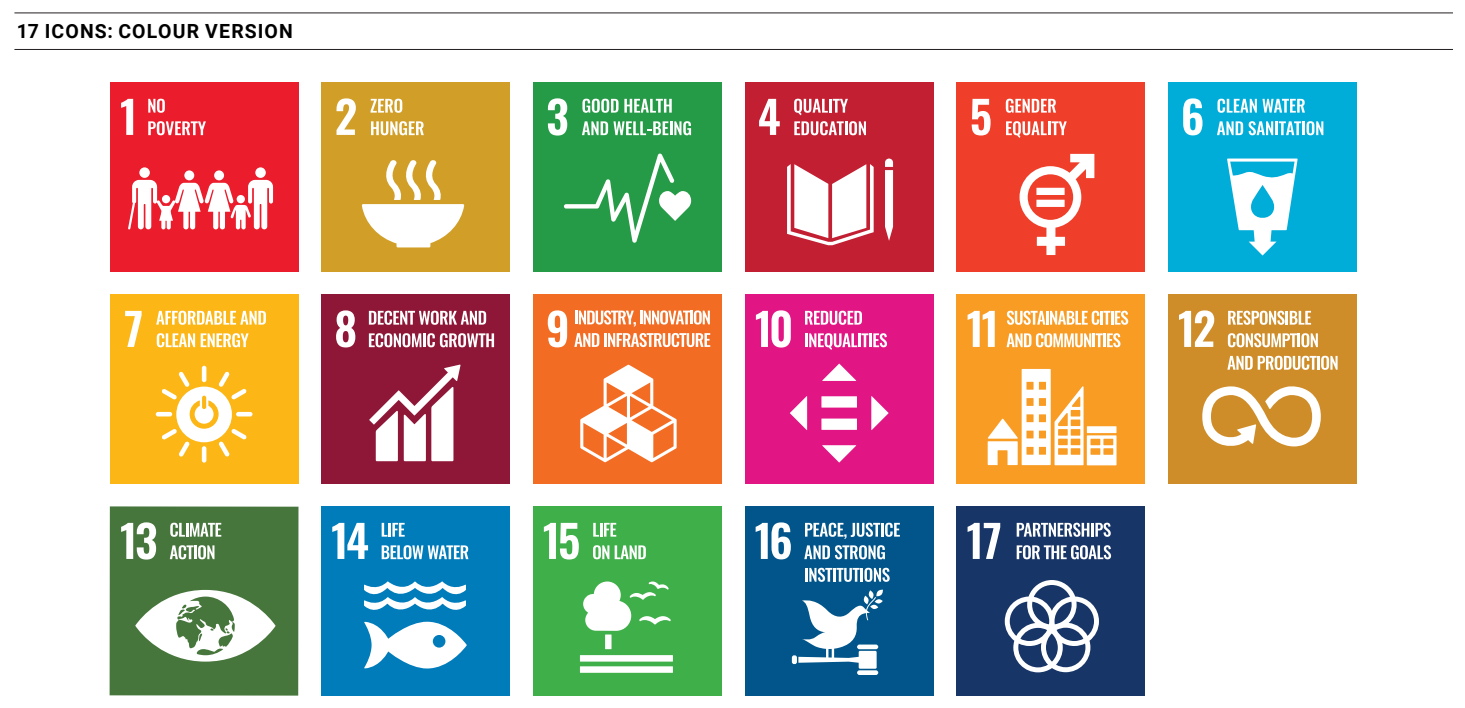

When an icon is on a square, that square must be proportional $1 \times 1$.

The white icon should be contained by its defined colour, or black background.

Do not alter the colours of the SDG icons.

Figure 6: The official guideline image on the SDG Icons, accessed on Sept. 15, 2020.
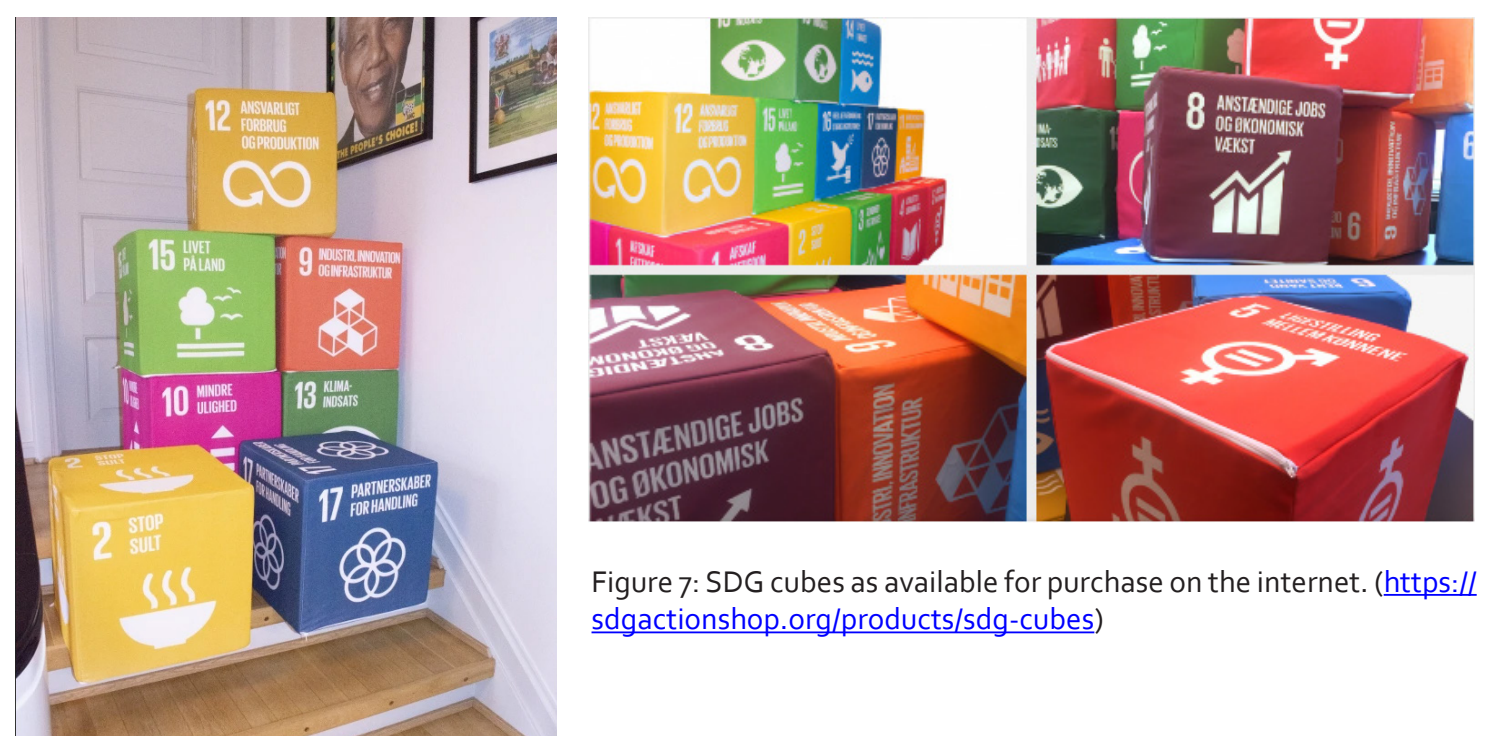

Figure 7: SDG cubes as available for purchase on the internet. (https:/l sdgactionshop.org/products/sdg-cubes) 


\section{Progress towards the SDGs by overco- ming hierarchies of knowledge}

The SDGs call for a transformation. In a profound sense, this rests on new ways of manipulating materials, based on fundamental changes in the "programmes" for manipulation. The SDGs are a set of "phenomena" (in the broadest sense of the word), which, using Michel Foucault's insights, form a „dispositive“. He explained the notion as „[...] a thoroughly heterogenous ensemble consisting of discourses, institutions, architectural forms, regulatory decisions, laws, administrative measures, scientific statements, philosophical, moral and philanthropic propositions-in short, the said as much as the unsaid. Such are the elements of the dispositive" (Foucault 1980). The secretariate of the SDGs, their website, its layout and its texts can be understood as part of the SDG dispositive. Why is it important to analyse the SDG as a dispositive? How the vast "SDG“-network of discourses and materialities is conceptualized has an important bearing on their implementation because power relations are shaped within this heterogeneous formation - despite the call for equality and participation inherent in the SDGs.

Knowledge has recently been conceptualized as a form of communicative action, with circulation as a constitutive feature (Secord 2004, 661), this ties in well with its role in a dispositive (Secord 2004). How knowledge is defined and which knowledge is (openly or tacitly) privileged is crucial. At a time when the status of knowledge is increasingly being contested, framing something as knowledge (or as information, as hyphenated or otherwise qualified particularity within knowledge, such as „embodied knowledge" or know-how) influences which status within the dispositive it will have. As stated on their website, „The Division for Sustainable Development Goals (DSDG) in the United Nations Department of Economic and Social Affairs (UNDESA) acts as the Secretariat for the SDGs, providing substantive support and capacity-building for the goals and their related thematic issues, [...] " and further: „The Division serves Member States, Major Groups and other stakeholders, as well as the general public, by providing wide access to information and knowledge for sustainable development, through its online Sustai-

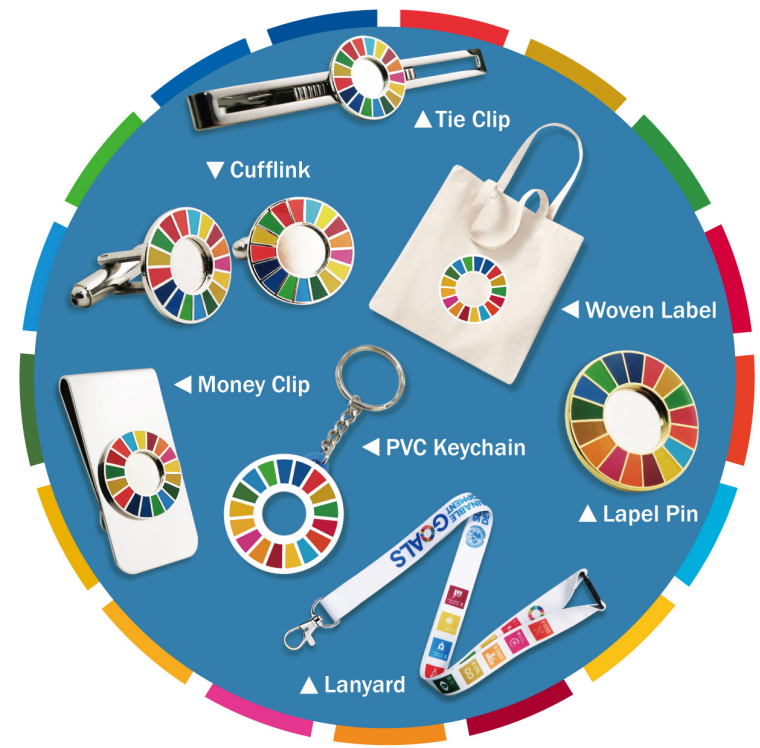

\section{Become a Promoter of the SDGS}

Welcome to custom a variety of SDGs products

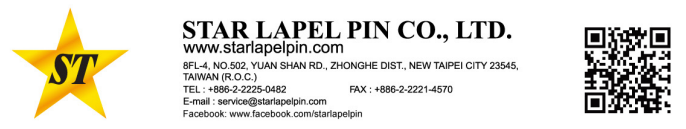

Figure 8: SDG merchandise (https://www.starlapelpin. com/wp-content/uploads/2019/09/SDGs-products.jpg).

nable Development Knowledge Platform and social media outlets." 6

The secretariat and its website act as gatekeeper and amplifier and therefore defines what is considered "Sustainable Development Knowledge“. Within the practice of the SDGs, „scientific“, seemingly unsituated, „pure“ knowledge as produced by the specialized social sub-system of scholars, academia is knowledge as such. All other knowledge needs qualifiers, such as "traditional ecological“ knowledge, "tacit" knowledge, sometimes even „expert" knowledge. Crafts such as weaving are (dis-)qualified by calling them „embodied“" „tacit“ even if this were a good description of the form of knowledge they produce.

The dispositive at work now claims to build capacity. But the sustainability transformation needs more than that, it needs third order change, as exemplified in Table 1. „First order change, which seeks effective-

6 https://www.un.org/development/desa/en/about/desa-divisions/sustainable-development.html 
ness or efficiency, is conformative and can be summarized as 'Doing things better'. Second order learning seeks examining and changing assumptions, It is reformative and can be described as 'Doing better things'. The third type of learning, epistemic learning, leads to a paradigm shift and is transformative. It can be summarized as 'Seeing things differently'." The third type has been identified as the type of scholarship reflexive modernity needs ${ }^{7}$.

Table 1: Orders of learning, their goals and short descriptions (Source: Sterling, 2011: 25).

\begin{tabular}{|c|c|c|}
\hline Orders of change/learning & Seeds/leads to: & Can be labelled as: \\
\hline First order change/cognition & Effectiveness/efficiency & $\begin{array}{l}\text { "Doin things better" } \\
\text { Confirmative }\end{array}$ \\
\hline $\begin{array}{l}\text { Second order change/meta- } \\
\text { cognition }\end{array}$ & examining and changing assumptions & $\begin{array}{l}\text { "Doing better things" } \\
\text { Reformative }\end{array}$ \\
\hline $\begin{array}{l}\text { Third order change/epistemic } \\
\text { learning }\end{array}$ & Paradigm change & $\begin{array}{l}\text { "Seeing things differently" } \\
\text { Transformative }\end{array}$ \\
\hline
\end{tabular}

But even if there is agreement on this need in the sustainability sciences, the process to „change mental models" underlying the transformation to third order learning remains vague. Dialogic processes are a common suggestion (Palma \& Pedrozo 2016).

Learning outcome taxonomies are of little help, because they are not transformation-oriented. After careful consideration, and a survey of even the most creative, striking violations of the SDG logo requirements (see Figure 9), it can be surmised that an Episteme of Sustainability might rather be achieved by engaging in embodied learning journeys by weaving the SDGs.

As detailed above, there is a great implementation gap in the SDG project. How can the embodied processes of craft contribute to the sustainability transformation? As Nithikul Nimkulrat, a textile artist, designer, researcher and educator originally from Bangkok, Thailand, argued, „In textiles as well as other material-designated disciplines, craft is understood not only as a way of making things by hand, but also as a way of thinking through the hand manipulating a material“ (Nimkulrat, 2010, p. 64 in Nimkulrat 2012). Craft is thus „a means for logically thinking through senses" (Nimkulrat, 2010, p. 75 in Nimkulrat 2012). This understanding follows the notion of craft as „a way of thinking through practices of all kinds" (Adamson, 2007, p. 7 in Nimkulrat 2012) and „a dynamic process of learning and un- derstanding through material experience" (Gray and Burnett, 2009, p. 51 in Nimkulrat 2012).

When asking if craft as a way of thinking through practices would foster the SDG implementation, weaving seemed a particularly apt plausible choice due to its morphological similarity to the networked character of the SDGs. Weaving entangles warp and weft, and their joints form the weave. The system is simple and yet allows for a myriad of patterns. Ellen Harlizius-Klück's work on the episteme of weaving as a foundation for the ability to think in an abstract way has inspired the project (Harlizius-Klück 2004). New forms of implementing the SDGs can profit from experiencing the complexity of controlling the pattern and the fabric's materiality simultaneously.

Learning outcome taxonomies are of little help, because they are not transformation-oriented. After careful consideration, including a survey of the most creative, striking depictions of the SDGs as process (in violation of the logo requirements, see Figure 9), a working hypothesis could be that the transformation, so far represented by unrelated cubes, might profit from a different representation. Such a representation should not lead to new forms of merchandise, but to new forms of learning journeys. Charlotte Holzer was willing to pioneer this learning journey, to document it and to share the products of her learning journey with us.

7 This paragraph is a quotation from Verena Winiwarter, Perspectives on Social Ecology: Learning for a Sustainable Future. In: $\mathrm{H}$. Haberl, F. Krausmann, M. Fischer-Kowalski, V. Winiwarter (Ed.) Social Ecology. Society-Nature Relations across Time and Space. Springer, Cham, 2016, 577-589. 


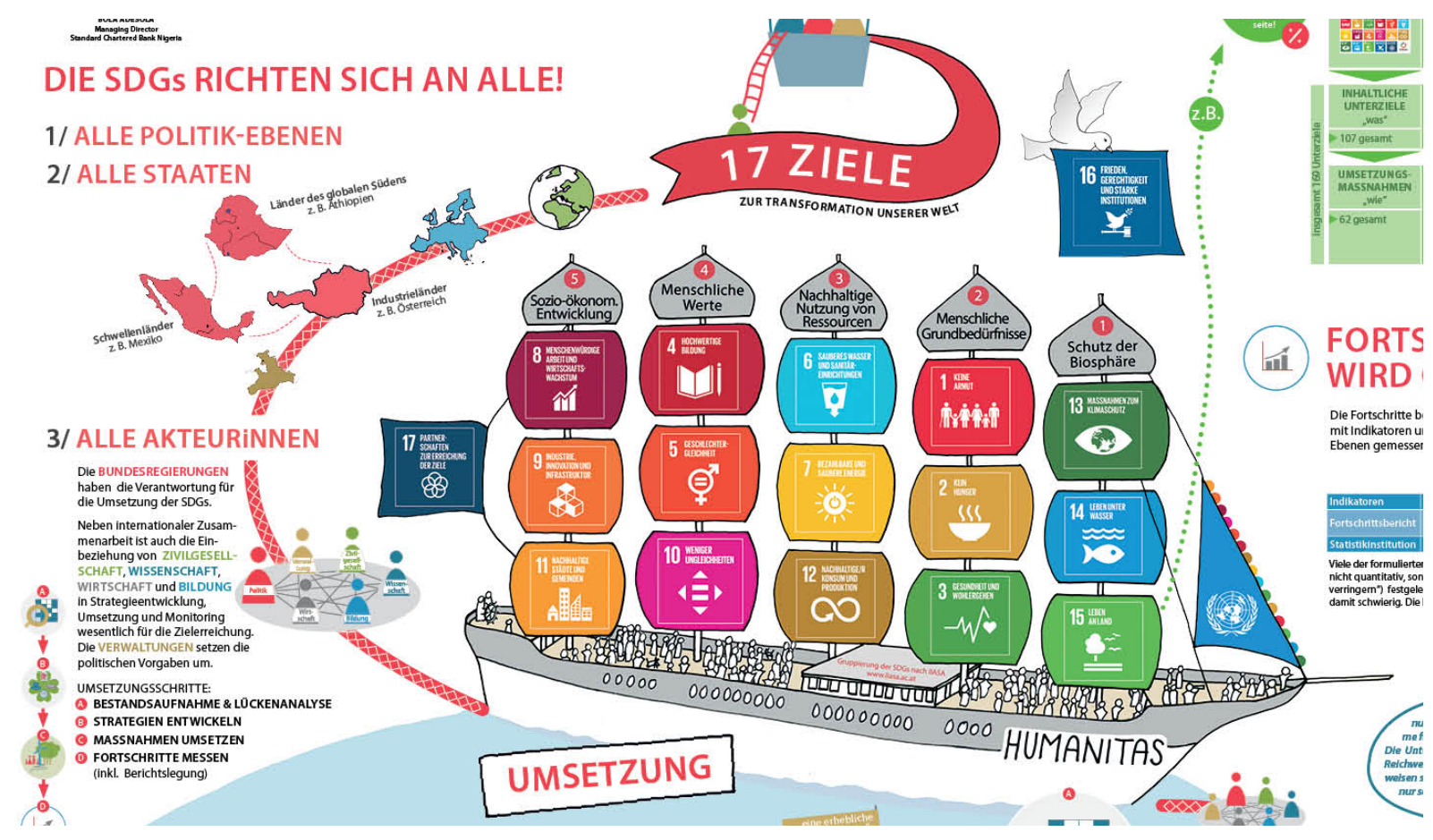

Figure 9: The central part of a poster by Visipedia, offering a powerful visual metaphor for the SDGs. https://www.visipedia.at/wp-content/uploads/2018/07/VISI SDG web s.jpg

\section{Tablet weaving the SDGs}

With as little material requirement as possible, without costly looms and technical implements that will not be available on a global level, tablet weaving was chosen for its global potential. Tablets can be made from many materials, including scrap cardboard or discarded plastic sheet material. Tablet weavers need a tree or another solid base to tie the end of their weave to, and a belt or cord around their waist for the other end. These requirements leave almost no-one behind, an important aspect of the SDGs.

The second reason is that, perhaps surprisingly, tablet weaving is one of the most complex weaving techniques, as it creates three-dimensional weaves (Griffiths 2018). It has been used for very intricate patterns in the past, and allows for a great deal of freedom in experimentation. ${ }^{8,9}$

In the context of the SDGs, the possibility of combining threads on tablets, of moving each tablet independently of others and not least, the ability to experiment with different techniques along one band - as a metaphor of time passing - all speak for the ability of tablet weaving to allow a change of the mental models, for $3^{\text {rd }}$ order learning (see Table 1 , above). The interaction with the materials, the respect needed for their possibilities and limits, the moving of hands and the designing of patterns in combination with the experience of bringing a designed pattern to bear on the band allow for third-order learning about the connectedness and the intricacies of the SDGs.

8 For a glimpse into the community, see https://www.tabletweavers.org/.

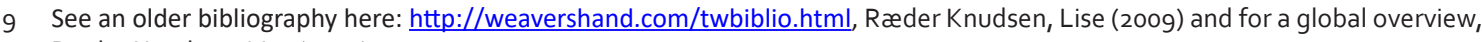
Ræder Knudsen, Lise (2014). 


\section{References}

Bundeskanzleramt "Österreich und die Agenda 2030. Freiwilliger Nationaler Bericht zur Umsetzung der Nachhaltigen Entwicklungsziele/ SDGs (FNU)", 2020. Wien: Bundeskanzleramt, https://sustainabledevelopment.un.org/content/ documents/26661VNR 2020 Austria Report German.pdf, Vienna: Austrian Federal Chancellery, https://sustainabledevelopment.un.org/ content/documents/26512VNR 2020 Austria Report English.pdf

Foucault, Michael „The Confession of the Flesh“ (1977) interview. In C. Gordon Power/Knowledge Selected Interviews and Other Writings. New York: Pantheon Books, 194-228, 1980.

Griffiths, Dave "Further attempts at untangling tablet weave”, 2018. https://penelope.hypotheses. org/674; accessed on March 16, 2021.

Harlizius-Klück, Ellen “Weberei als episteme und die Genese der deduktiven Mathematik. In vier Umschweifen entwickelt aus Platons Dialog Politikos." Disseration Oldenburg Universität, 2004.

Independent Group of Scientists appointed by the Secretary-General "Global Sustainable Development Report 2019: The Future is Now - Science for Achieving Sustainable Development." New York: United Nations, 2019. https://sustainabledevelopment.un.org/content/documents/24797GSDR report 2019.pdf

Lutz et al. "Years of Good Life (YoGL): A new indicator for assessing sustainable progress." Laxenburg: IIASA, 2018. http://pure.iiasa.ac.at/id/ eprint/15402/1/WP-18-007.pdf

Nimkulrat, Nithikul "Hands-on intellect: Integrating craft practice into design research." International Journal of Design 6(3), 1-14, 2012.

OECD "A Territorial Approach to the Sustainable Development Goals Synthesis report”, 2020. https:// www.oecd.org/regional/a-territorial-approachto-the-sustainable-development-goals-e86fa715en.htm
Österreichische Akademie der Wissenschaften (Hg.) "Global Sustainable Development Goals in a Mediatized World." Akademie im Dialog 18, 2020. https://www.oeaw.ac.at/fileadmin/NEWS/2020/ PDF/Webversion_AiD_18.pdf

Palma, Lisiane C. and Pedrozo, Eugênio Á. “Transformative learning to promote sustainability: inserting the third level of learning in management programs." Brazilian Journal of Science and Technology 3, 9, 2016.

Ræder Knudsen, Lise "Rekonstruktion des Webvorganges bei der Dürrnberg-Borte.” In K. Grömer und T. Stöllner (Hg.) Ein abgerissener Ärmel aus dem Salzbergwerk Dürrnberg. Neue Erkenntnisse zur Brettchenwebtechnik in der Eisenzeit in Mitteleuropa. Jahrbuch des Römisch-Germanischen Zentralmuseums 56, 119-121, 2009.

Ræder Knudsen, Lise "Global Textile Encounters. Ancient Running Animals: Tablet-Woven borders from China and Norway". Oxford \& Philadelphia: Oxbow Books, 37-48, 2014.

Sachs, Jeffrey D., Schmidt-Traub, Guido, Mazzucato, Mariana, Messner, Dirk, Nakicenovic, Nebojsa, and Rockström, Johan "Six Transformations to Achieve the SDGs." Nature Sustainability 2, 805-814, 2019. https://www.nature.com/articles/ $\underline{\text { s41893-019-0352-9 }}$

Secord, James A. "Knowledge in Transit." Isis 95 (4), 654-672, 2004.

Sterling, Stephen "Transformative learning and sustainability: sketching the conceptual ground." Learn Teach High Educ 5, 17-32, 2011.

TWI2050 - The World in 2050 "Innovations for Sustainability. Pathways to an efficient and post-pandemic future. Report prepared by The World in 2050 initiative. International Institute for Applied Systems Analysis (IIASA)." Laxenburg: IIASA, 2020.

UN Department of Global Communications "Sustainable Development Goals. Guidelines for the use of the SDG Logo including the Colour Wheel, and 17 Icons", 2018. https://www.un.org/sustainabledevelopment/wp-content/uploads/2019/01/ SDG Guidelines January 2019.pdf 
Winiwarter, Verena "Perspectives on Social Ecology: Learning for a Sustainable Future." In H. Haberl, F. Krausmann, M. Fischer-Kowalski and V. Winiwarter (ed.) Social Ecology. Society-Nature Relations across Time and Space. Cham: Springer, 577-589, 2016.

Winiwarter, Verena (Hg.) "Umwelt und Gesellschaft - Herausforderung für Wissenschaft und Politik." KIOES Opinions 8, 2018. Vienna: Austrian Academy of Sciences. https://www.oeaw.ac.at/fileadmin/kommissionen/kioes/pdf/Publications/ Opinions/KIOES Opinions 8.pdf 


\title{
Thinking through weaving - An Experimental Approach to the UN Sustainable Development Goals
}

\author{
Charlotte Holzer
}

\section{Introduction}

The United Nation has initiated the „Agenda 2030“ to foster global sustainable development. The great challenge of this agenda is to find a balance between its economic, social and environmental dimensions. The 17 goals and their 169 specific targets have given rise to an enormous number of graphic representations, working schedules, publications, events and much more. None of them seem to have the power to induce a transformation into a more sustainable way of existence. This experimental approach focuses on the inseparable nature of the goals by means of physically interweaving them and seeks to go beyond representation.

The starting point to this rather unusual endeavor were Verena Winiwarter's reflections on the current separate handling of the SDGs by political stakeholders and research institutions. She voiced her concerns over attempts to fulfill the „Agenda 2030“ by ignoring common trade-offs between the SDGs and proposed to overcome that approach in her statement „Weaving a new fabric of society. Reflections on the Sustainable Development Goals and the links between them" (See Appendix). In her role as a member of the Deutsches Museum board of trustees, she contacted Dr. Ellen Harlizius-Klück to ask for professional assistance from the field of textile technology. Charlotte Holzer, author of this part of the report, joined the cooperation with the task to carry out the actual weaving.
The main objective was to lay the groundwork for weaving workshops with stakeholders, politicians and scientists responsible for the implementation of the SDGs. The hypothesis was: Letting stakeholders experience the complexity and possibilities that lie in the design of ribbons and in the simultaneous manipulation of all goals (represented by colored threads) would benefit their decision-making skills. In this pilot project, the development of a booklet with technical constructions for such workshops was not the aim. However, by going through the learning process from the point of no knowledge to actually designing SDG ribbons, the outline of a step-to-step approach emerged.

During tablet weaving and the production of increasingly complex fabrics, that interlinked the SDGs, a cognitive process took place, that lead to the experiment becoming structured. Altogether, the project spanned from summer 2019 to autumn 2020 . The phases of actual weaving were alternated with long periods of reflection, planning, documentation, discussion or pauses. Only when the practical work paused, the methodology became apparent and it was then possible to identify eight steps, that fell into three categories. 


\begin{tabular}{|c|c|}
\hline Category & Steps \\
\hline $\begin{array}{l}\text { The technique } \\
\text { Beginners learn how to do tablet weaving by following basic instruc- } \\
\text { tions. Ideally, an experienced weaver guides through the first steps and } \\
\text { then there is sufficient time for individual learning processes. In this } \\
\text { project, Ellen Harlizius-Klück gave the instructions on the weaving tech- } \\
\text { nique and provided literature about the design process. }\end{array}$ & $\begin{array}{l}\text { Learn the technique } \\
\text { Master the patterns }\end{array}$ \\
\hline $\begin{array}{l}\text { The representation } \\
\text { The next stage is to get familiar with the SDGs by visualizing them in dif- } \\
\text { ferent patterns. Very early on in the project, it was decided to allocate a } \\
\text { specific thread color to each of the } 17 \text { goals, according to the official UN } \\
\text { design. In addition, background colors (white, pastel blue / green) were } \\
\text { added in some ribbons. }\end{array}$ & $\begin{array}{l}\text { Introduce the SDG content } \\
\text { Weave the SDGs and de- } \\
\text { sign patterns } \\
\text { Weave SDG patterns } \\
\text { Refine the result }\end{array}$ \\
\hline $\begin{array}{l}\text { The imaginative synthesis } \\
\text { The third step involved the materializing of personal thinking processes. } \\
\text { The experience from this project showed that a clear set of content re- } \\
\text { quirements stated by an SDG expert played an essential role in the plan- } \\
\text { ning and designing the ribbons. }\end{array}$ & $\begin{array}{l}\text { Introduce individual thin- } \\
\text { king } \\
\text { Practice „weave thinking" }\end{array}$ \\
\hline
\end{tabular}

Together with a written and photographic documentation, the ten ribbons created represent the project outcome, upon which further interpretation, also within this report, is based.

\section{The experimental setting}

The great advantage of tablet weaving is the very simple and small equipment needed to produce the woven fabrics. A set of cardboard cards with four holes, colored cotton threads, a wooden shuttle and two strings to attach the construction to a doorknob, stool or railings were used (Fig. 1). The simplicity of tablet weaving equipment allowed working at many locations. As a result, the interaction with the author's social environment often had an impact on the weaving process.

The methodological approach was a combination of background research and knowledge exchange on the SDGs with the practice of tablet weaving. Additional topics included creative thinking and related cognitive processes, complex decision-making with a focus on space exploration, knowledge practice and strategies of climate action.

The team consisted of three researchers from various fields: environmental history, textile art / mathema-

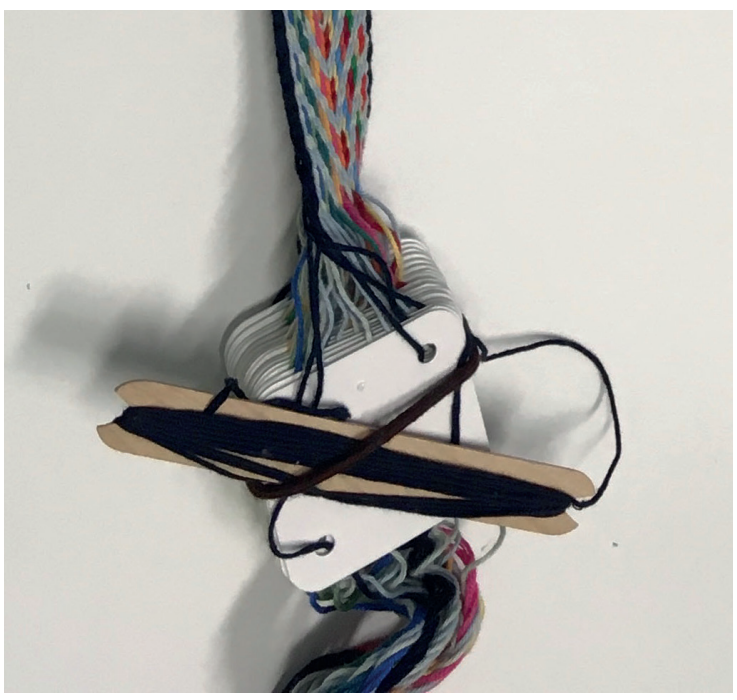

Figure 1: Threaded cards and wooden shuttle.

tics / philosophy and conservation. Verena Winiwarter, chair of the Commission for Interdisciplinary Ecological Studies at the Austrian Academy of Sciences initiated the project. She contributed the contentrelated aspects and decided on the textile technique to be experimented with, namely tablet weaving. Ellen Harlizius-Klück, who leads the ERC project PENELOPE - A Study of Weaving as Technical Mode of Existence, acted as an expert adviser. She also recommended the author to carry out this experiment 
of knowledge practice, whom she knew from her $\mathrm{PhD}$ project at the Deutsches Museum. All three participants have skills in interdisciplinary work from previous projects and from their professional occupation. Furthermore, a connection between their everyday theoretical work with experience in textile techniques is practiced by them.

- As a conservator Charlotte Holzer is used to link the knowledge of the humanities with the natural science, in order to understand and preserve cultural heritage. Being specialized on textiles means that she is familiar with the materials and techniques from an analytical standpoint as well as with the actual handling of flexible fiber structures.

- Prof. Verena Winiwarter is an environmental historian, trained initially as a chemical engineer, after years of practice, got a university degree in history and communication sciences. She was Dean of the faculty of interdisciplinary studies of Klagenfurt University, in which capacity she also researched and published on interdisciplinarity. As chair of the Commission for Interdisciplinary Ecological Studies at the Austrian Academy of Sciences, she has taken on the task of working for the implementation of the SDGs in Austria and beyond.

- Dr. Ellen Harlizus-Klück is Principal Investigator of the ERC project PENELOPE (HORIZON 2020, Grant No. 682711), interested in weaving as a procedure of establishing order and complexity at the same time. Being educated as mathematician, she especially draws on the fact that weaving is a binary art that nevertheless can reach high levels of representation by combining algorithmic and creative parts. She also investigates traditional and ancient weaving as a mode of existence encompassing not only technical but also social and environmental order.

The articulation and exchange of thoughts on the current state of the project played an essential part in the process. Opportunities to communicate included two meetings between the author and Verena Winiwarter in Vienna, regular talks with Ellen Harlizius-Klück in the research institute, e-mail correspondence and a final workshop with all participants. This workshop was also joined by Dr. Annapurna Mamidipudi, who is part of the PENELOPE project. In addition, infor- mal talks with colleagues from the Deutsches $M u$ seum, who were not familiar with the SDG weaving concept contributed to method development, insofar as the principals had to be explained in an understandable way.

The following key elements taken from the proposal of Verena Winiwarter and discussions guided the author in her SDG weaving learning process.

- In order to balance the economic, social and environmental dimensions of the SDGs, five main areas „People - Planet - Prosperity - Peace Partnership" have to be handled in a non-hierarchical way.

- The SDGs are „inextricably linked strands of society and nature“.

- The Agenda 2030 is a collective journey for humanity, which is best represented by No. 17 „Partnership for the Goals“.

- The contradictions between some of the goals reflect their roots in the real world.

- In this project three different forms of visualization were reflected on and processed in the ribbons:

- According to network analysis, the goals No. 10 „Reduce Inequality“ and No. 12 „Responsible Consumption and Production“" are key levers in the attempt to reach sustainable development.

- The biosphere goals are fundamental, as shown in the wedding-cake diagram developed by Carl Folke and his team at the Stockholm Resilience Centre, Stockholm University (Fig. 10).

- The synergetic linkages and trade-offs between the goals, examined by meta-level analysis (Independent Group of Scientists appointed by the Secretary-General 2019, Box 1-2). 


\section{Technical, representative and imaginative woven ribbons}

Step-by-step the reader is now invited to follow a description of the methodological approach, illustrated by the resulting ribbons. At the end of each section interpretation is given for each step, reflecting on how the planning and execution of each ribbon lead on to the next. Thereby, an attempt is made to explain how the initial aims of the project were aspired, questions answered, and limitations met on the way.

\section{Learn the technique}

To get familiar with the task ahead, the author joined an introduction into the art of tablet weaving, by Dr. Harlizius-Klück at the PENELOPE Laboratory in the Museum for Plaster Casts of Classical Sculptures Munich. After a short theoretical description of the process, an easy pattern and a limited number of two to three colors were chosen. The cards then had to be threaded according to the pattern sheet, the warp threads knotted at the end and the whole stake of cards sorted by the threading direction (one half "S“, the other one "Z"). Using a thread loop, the bundle was attached to the vertical loom available, in order to sort the tangled warp threads, knot them and put weights at the bottom. (In the following setups, the lower end of the ribbon was tied to a chair instead of using weights.) The last preparatory step was to wind a weft thread on a wooden stick with notches at both sides.

The weft thread was introduced, and the stack of cards turned in one direction. Changing the direction meant to mirror the pattern and also to disentangle the warp threads at the bottom of the ribbon. Alternatively, this was achieved by opening the knot. When the tension was removed from the structure (at the end of the first lesson), it was essential to tie the cards together.

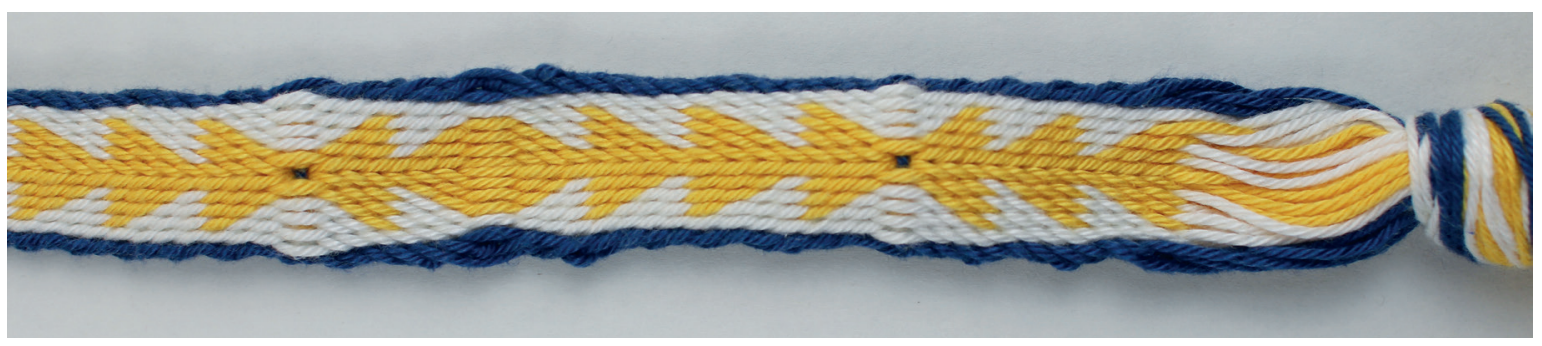

Figure 2: Detail of ribbon No. 1, showing a threaded-in design with variations of the pattern, due to the turning direction of the cards.

$\begin{array}{lllllllllllll}\mathrm{S} & \mathrm{S} & \mathrm{S} & \mathrm{S} & \mathrm{S} & \mathrm{S} & \mathrm{Z} & \mathrm{Z} & \mathrm{Z} & \mathrm{Z} & \mathrm{Z} & \mathrm{Z}\end{array}$

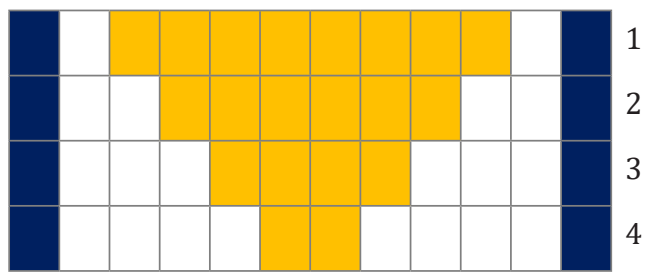

Figure 3: Threading pattern for ribbon No. 1

Upon finishing the ribbon, an illustrated documentation was made, in which the learning effects and the experienced emotions were noted beside the respective sections (See appendix).
In this first ribbon, the design resulted from different turning options that were tried with the initial threaded-in weaving pattern. For someone who has never done tablet weaving before, it was an interesting experience to realize the time-shift between turning the cards and actually producing the pattern in the ribbon.

It was motivating that one could arrive from a theoretical introduction to already weaving part of a ribbon within an afternoon. However, within that timeframe, only a first notion or intuitive grasp of the technique was acquired and a level of deeper understanding could not be reached. That was left for finishing this ribbon at home, go on weaving with the 
help of guiding books and facing mistakes that needed to be unravelled.

A noteworthy characteristic of tablet weaving is the underlying, yet invisibly connecting role of the weft. The weft threads run from selvedge to selvedge and becomes embedded between the warp threads that cover them. They only appear as small dots at edges of the ribbons, at the turning points between the cards changing direction and sometimes, when weaving mistakes happen. Most designs in tablet weaving instructions even recommend to use the same color for the warp threads on the edge of a ribbon and the weft threads, in order for them to blend in. Playing with this technical concept behind tablet weaving became one of the means to reflect on and to visualize the linking element in the background.

\section{Master the patterns}

In order to learn how to actively manipulate the threads and create designs during the weaving process, a sequence of patterns was tried using a light-darkeffect. Two light and two dark threads were put into one card and the selvedge was made unicolor. While the cards with the threads on the border of the ribbon where left unchanged, the ones in the middle were alternated:

- the starting point for each color by turning cards individually,

- the threading direction by flipping them and

- the turning direction of all or selected cards.

The choice of color was led by a need for simplicity, so the focus could lie one the weaving technique. However, already in this step, the yellow, blue and red in warp as well as the dark blue weft were selected with their meaning for the SDG color coding in mind.

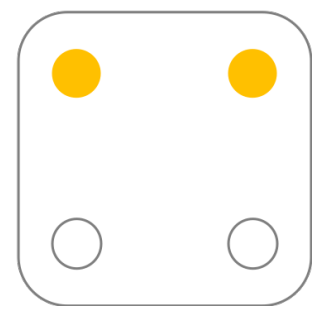

Figure 4: Schematic drawing of the cards, that were threaded with two light and two dark colors.

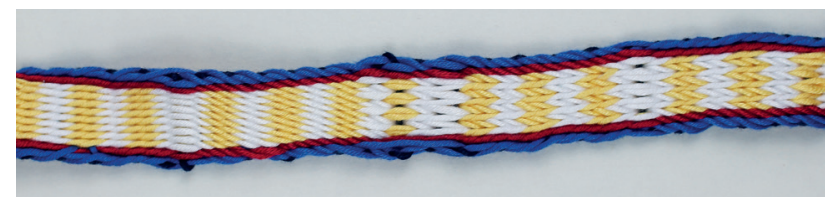

Figure 5: Detail of ribbon No. 2 with horizontal stripes.

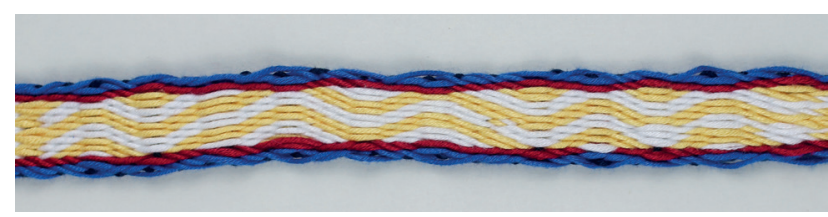

Figure 6: Detail of ribbon No. 2 with diagonal stripes.

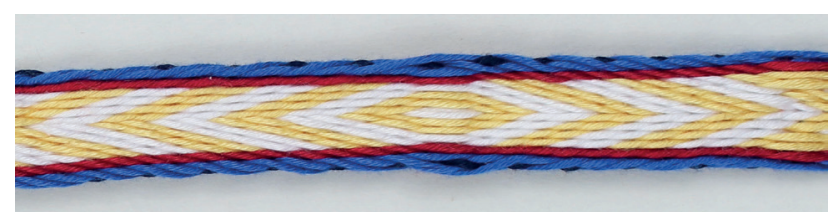

Figure 7: Detail of ribbon No. 2 with a sharp angle pattern.

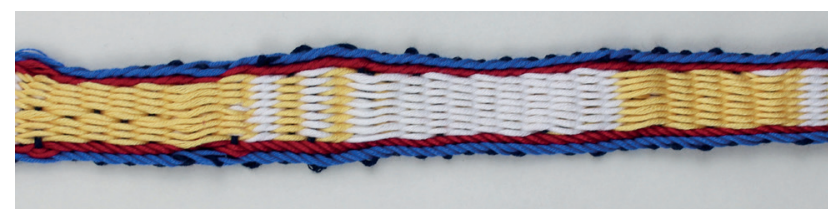

Figure 8: Detail of ribbon No. 2 woven in the doubleface technique.

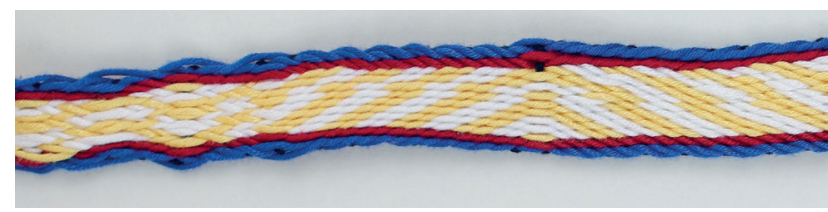

Figure 9: Detail of ribbon No. 2 with wide diagonal stripes.

After having understood the concept of threaded-in weaving patterns, another approach was chosen to begin mastering the technique. The light-dark effect allowed to see how the pattern changes, if the position of the threads in the cards and the threading directions were alternated. By trying out a set of instructions (Crockett 1994, pp. 83-102) a repertoire of patterns was acquired. While weaving that ribbon, changes between patterns could be practiced as well as dealing with errors (correcting them or observing how they unfold in the fabric). Also, the importance of empty space or „white space“ for the visualization of patterns was identified. 


\section{Introduce the SDG content}

Since the aim of the weaving process included handling all the SDGs as inseparable, from this point onwards, all of the 17 SCG colors were interwoven. Since 17 is a prime number, that can only be divided by itself, a grouping, inspired by the wedding-cake model of the Stockholm Resilience Centre at Stockholm University (Fig. 10), was chosen: One tablet weaving card can hold a maximum of four different colors and in this case the colors of goal one to 16 were allocated to fours cards. The dark blue colored thread representing number 17, Partnership for the goals, was used for the weft.

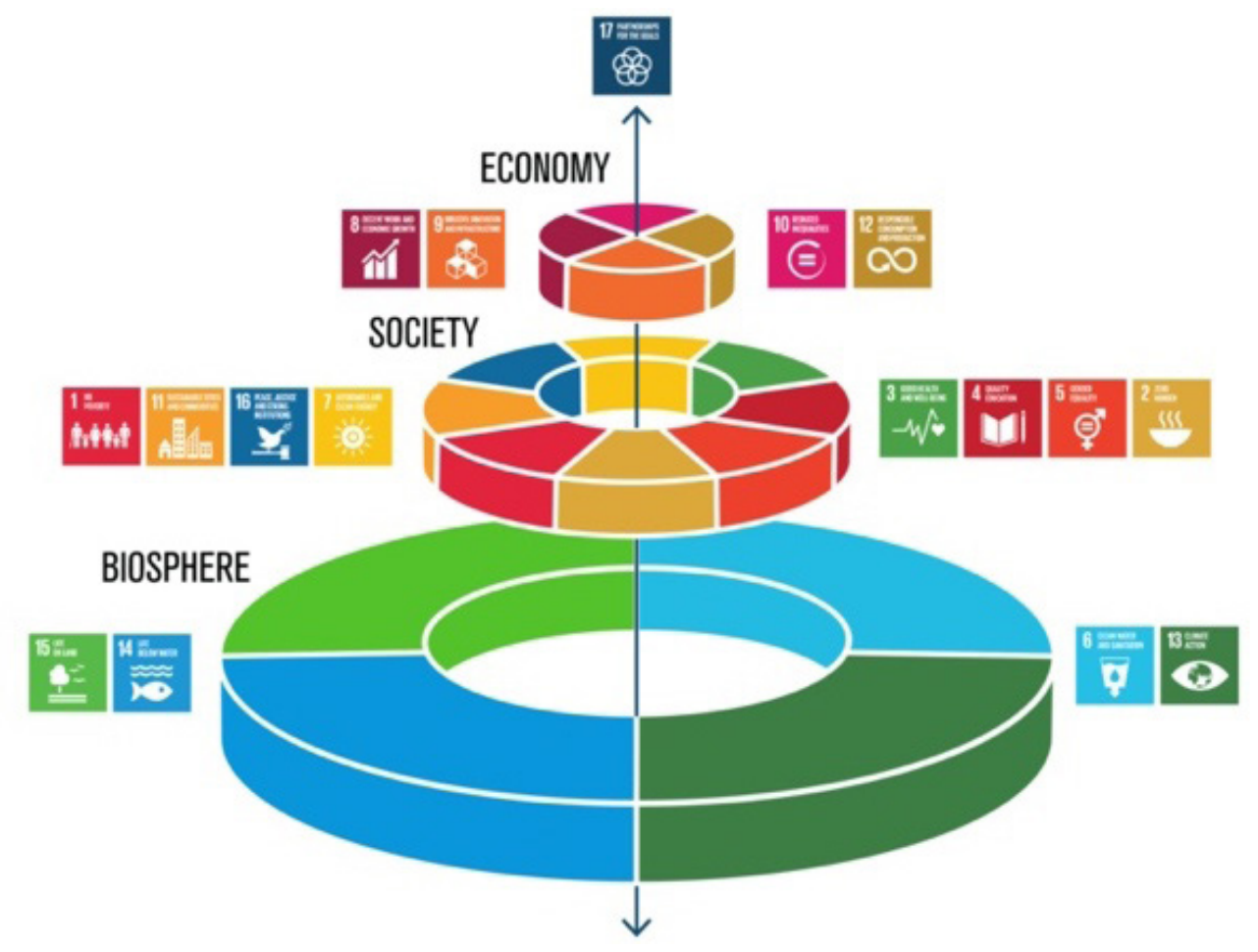

Figure 10: Wedding-Cake-Model of the Sustainable Development Goals, Credit: Azote Images for Stockholm Resilience Centre, Stockholm University.

Two versions were tried: putting the four colors of a group onto one card or on the same position of four adjacent cards. For the border a white thread was used, representing light / enlightenment / the role of science for achieving the SDGs.

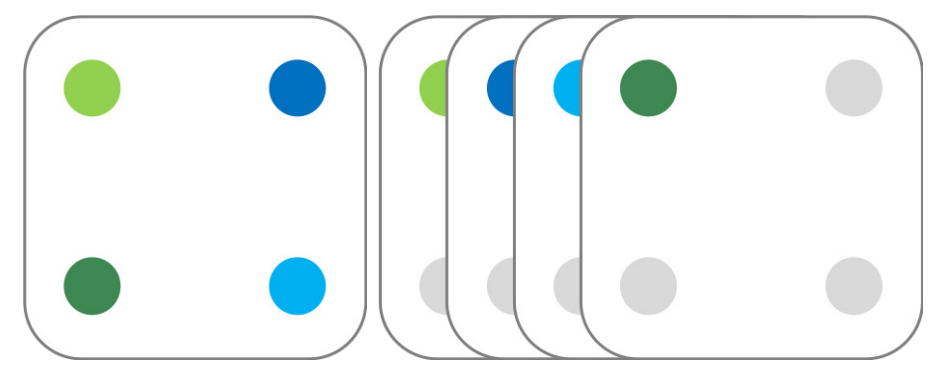

Figure 11: Schematic drawing of the cards, that were threaded with a group of four colors each or in the same position of four cards. 


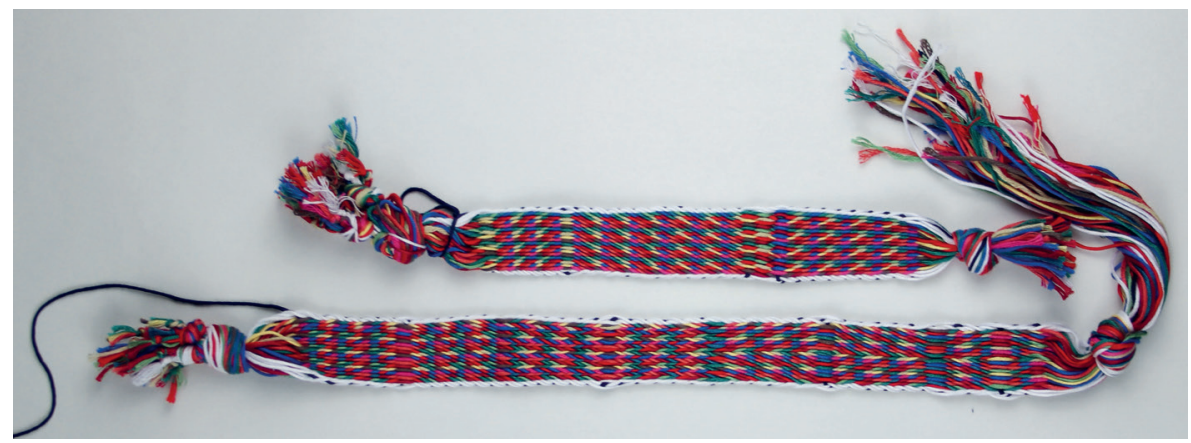

Figure 12: Ribbon No. 3 (above) and No 3. (below).

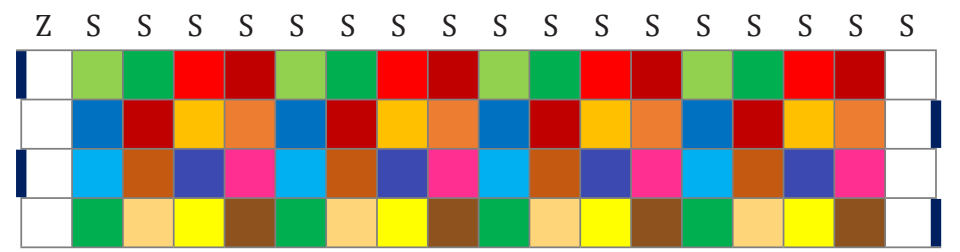

Figure 13: Threading pattern for ribbon No. 3.
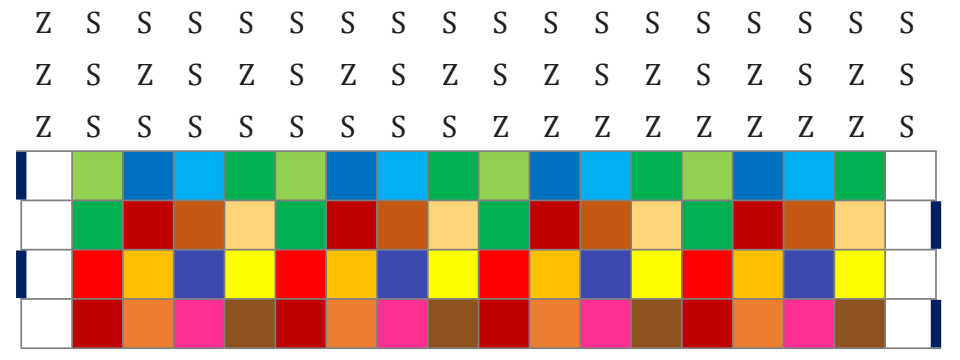

Figure 14: Threading pattern for ribbon No. 4 with the changing card slant.

From a technical point of view, these ribbons presented no further learning experience. However, to save threads, the change in pattern was done by rethreading the cards with the new sequence. When looking at a stack of four cards holding four differently colored threads, the act of changing the position of one thread felt like working within the system of a matrix.

An attempt to show synergies or trade-offs between the SDGs in this ribbon failed - probably due to the lack of detailed knowledge about the content and a clear specification of the goals to be compared.

\section{Weave the SDGs and design patterns}

In the next ribbon a combination of the two preceding weaving approaches was applied: the technique of light-dark-effects executed with all colors on a white background. The selvedge and weft threads in dark blue, representing Partnerships for the goals, framed the ribbon. Within these boundaries, the original numbered sequence of the SDG was maintained. Some technical difficulties were faced when it came to controlling the appearance of the pattern on the front or back. At this point this issue was ignored and left for a later stage in the learning process. 


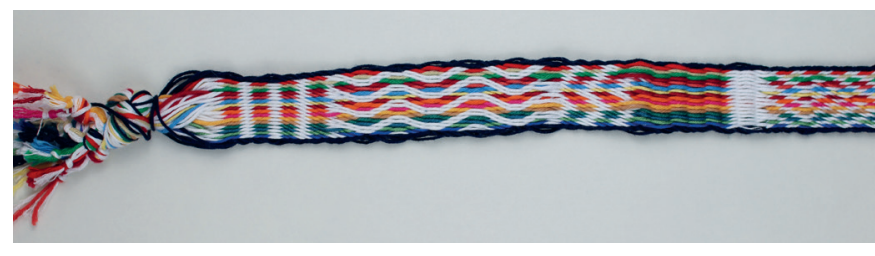

Figure 15: Detail of the beginning of ribbon No. 5 .

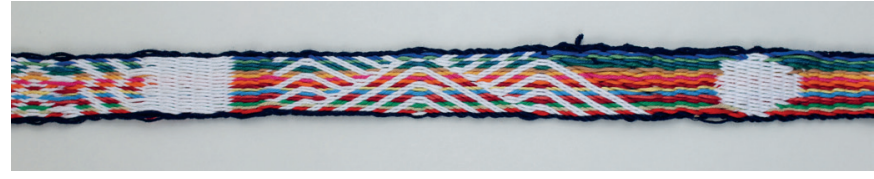

Figure 16: Detail of ribbon No. 5 showing the diagonal strips and a circle.

The ribbon again served for the familiarization with different modes of representation. The connecting and separating effects of the diagonal patterns (diagonals and waves) was tried and also the visual effect of the goals running along each other. Personal limitations were met when it came to the realizations of circles and change into white space (floating threads). The white background also dominated the design, which is why it was decided to look for contrasting, but unobtrusive colors.

\section{Weave SDG patterns}

The pattern of wide diagonal stripes, running over the whole ribbon came to be the guiding design for the final representative ribbons. A similar layout to the one before was chosen, however the appearance of the color followed an environmental theme: in going through the targets that describe and connect the SDGs, goals with a similar amount of reference to the biosphere category of the wedding cake model were grouped together as can be seen below.

Following the overall topic of this ribbon, the background from which the goals gradually appeared, was held in greenish-blue colors in a pastel shade.

At the end, it was attempted to weave a sandglassshaped form. The inspiration for that pattern derived from the cover of the UN SDG report ,The Future is Now".

When creating this ribbon, the initial thought was that life on planet earth is the fundamental condition for social or economic dimensions of sustainability. By starting the diagonal patterns with the biosphere goals, it was suggested that in caring for the environment, basic knowledge on caring for each other in general could be acquired. In addition, many options that would have initially been open to reach other goals are ruled out right from the beginning. For example goal unlimited access to energy would jeopardize the only planet currently available for humanity.

The technically most challenging aspect of creating this fabric was to introduce the new goals at the right moment (see the numbers). It was felt that the experience reflects the planning and implementation of a multi-faceted project with many different participants. While it took some exercise to arrive from the initial background to the diagonals, it proved even more difficult to change back to the uni-colored area. In both ribbons, this can be seen in the floating threads that were just bound again by the weft after some turns with all the cards.

\section{Climate action Life below water Life on land Clear water and sanitation}

4-9 Industry, innovation and infrastructure Sustainable cities and communities Responsible consumption and production

2-3 Zero hunger Affordable and clean energy Decent work and economic growth

1 No poverty Good health and well-being Quality education

Gender equality Reduce inequality Peace, Justice, Strong Institutions

Figure 17a: Schematic drawing of the concept behind ribbon No. 6 and No. 7 with the SDG tiles being introduced. 


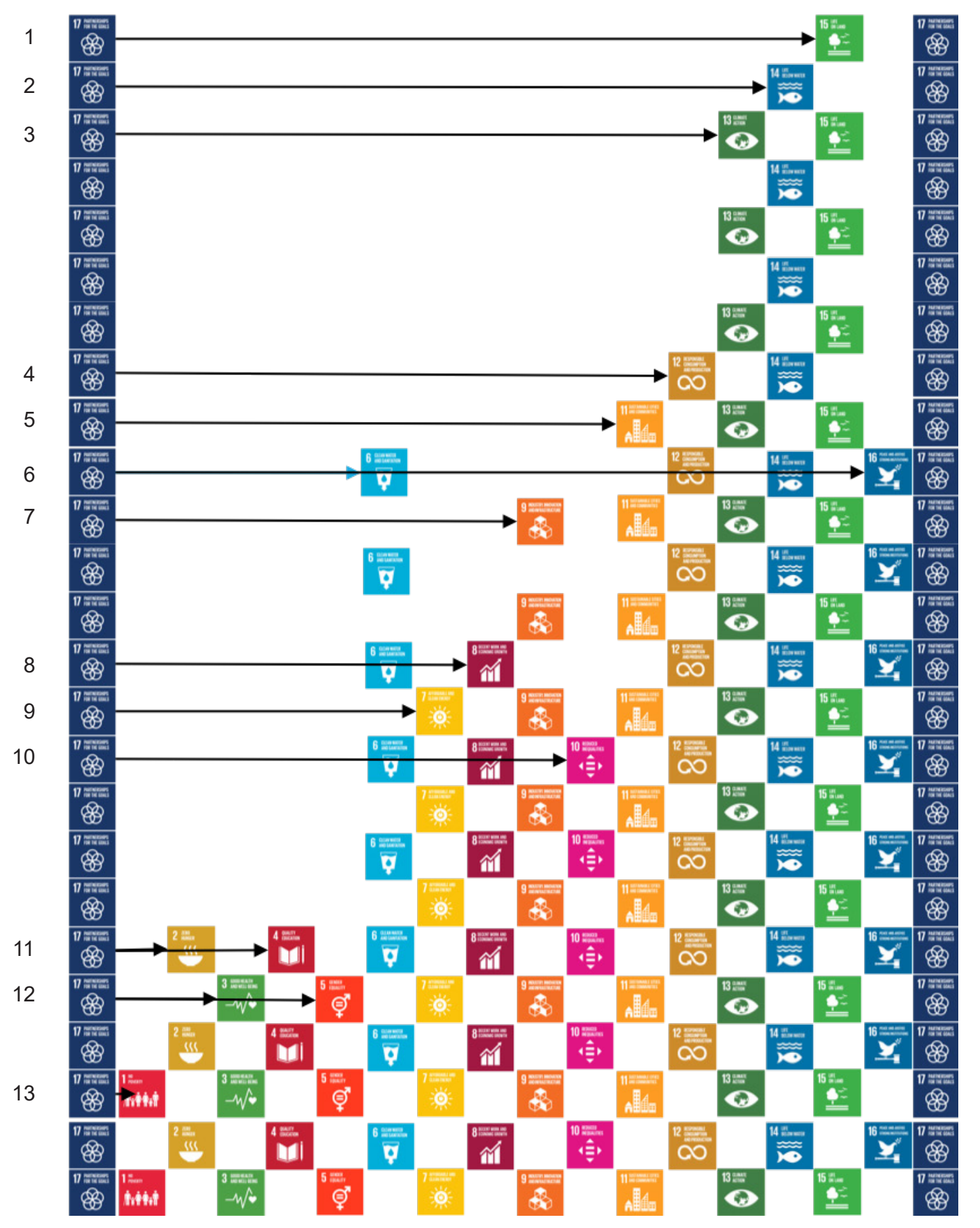

Figure 17b: Schematic drawing of the concept behind ribbon No. 6 and No. 7 with the SDG tiles being introduced. 


\section{Refine the result}

In the second version of this ribbon, the requirements and advice from Verena Winiwarter and Ellen Harlizius-Klück were reconsidered by

a. Back coupling the achieved weaving reflections with the original objectives specified in the project proposal,

b. Solving problems from the beginning and the end, to meet in the middle.

While the beginning was designed in the same way, as before, the combined SDG colors faded out at the end merged again with the greenish-blue background. The last remaining goals were Reduce inequality and Responsible consumption and production, which proved to be driving forces in achieving the SDGs, as was shown by a network analysis (Winiwarter 2018, S. 22). Again, the other goals were ranked by their relation to those two social driving forces by going through the contents of the targets.

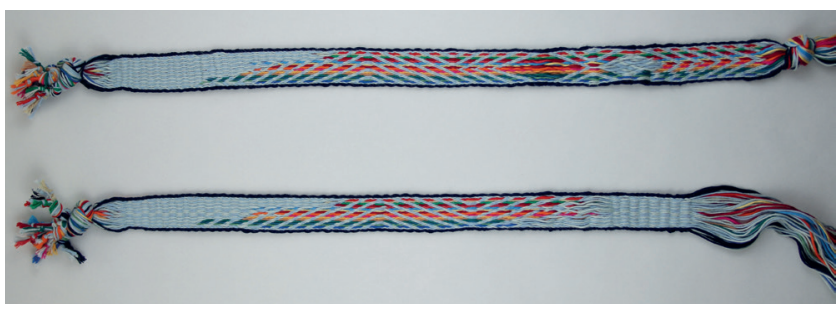

Figure 18: Ribbon No. 6 (above) and No. 7 (below).

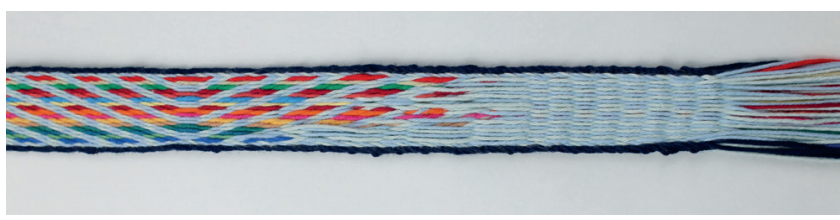

Figure 19: Detail of the end of ribbon No. 7 with the colors fading out into the background.

In finishing the second version of this ribbon, an endpoint in finding a way to represent the SDGs was reached. However, the aim of the experiment was not to produce another aesthetically appealing representation of the 17 SDGs, but to gain more understanding in how to deal with the complexity of reaching them.

\section{Introduce individual thinking}

By now, a certain ability to express individual ways of thinking on how to connect the SDGs with tablet weaving was reached. From this point on, the ribbon served as an „extended mind“ to outsource thinking (Clark and Chalmers 1998). The grouping of the goals in relation to the biosphere was maintained and Partnership for the goals still acted as a framing and connecting element (selvedge and warp). In contrast to the earlier ribbons, two goals were chosen for the background: The blue from Peace, Justice, Strong Institutions was threaded into the cards with the other two biosphere-unrelated goals (Gender equality, Reduce inequality) and given a central position in the pattern. Clean water and sanitation was allocated the role of a connecting and flowing actor between all other goals. This choice was inspired by a theory based on the change that is caused by colors in water, opposed to the reflection of light causing the perception of colors (Arnold 2019). Templates for threadedin-patterns from „Tablets at Work“ could be used as a basis for the pattern (Wollny 2019, p. 107-119). The effects of different turning points were observed during the weaving.

While working on the ribbon, interesting (subjective) experiences were made, about how thoughts could look like in a fabric. The process elicited feelings about dead-ends or approaches worth pursuing by the author. The ulterior motive of making it was not to find a solution for the implementation of the agenda 2030, but to try expressing and processing information by manual means.

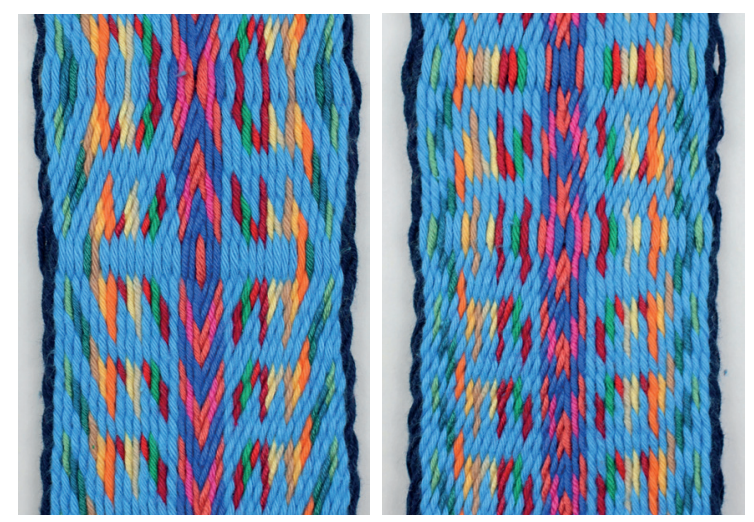

Figure 20: Detail of ribbon No. 8 from both sides. 
It was felt that the dominance of the light blue, representing water, gave the design a very lively appearance, but at the same time induced a feeling of discomfort. Since „water" / blue was chosen to represent change and flow, it gave the author the impression that change and speed in itself are not beneficial in a project and aspects of reflection need to be added.

The central strip had a much more dividing effect than intended, therefore this element was not used further. The combination of more than one aim on a card was maintained to deal with the fact that the 17 of SDGs are a prime number. The sequence of colors, representing the SDGs started with the greens and blues of the biosphere goals and continued with those, that had less and less direct links to the environment.

\section{Practice „weave thinking“}

For the last two ribbons, no additional note-taking or sketching was used to plan and design the pattern. The sources of knowledge consisted of the experience gained through practicing tablet weaving, the memories on the SDG contents (literature, discussions, handling the colors) and the ribbons made until then. At this point experience took over and sidestepped the typical idea of design/drawing first in favor of experiments based on the knowledge from within.

The reflections in the weaving pattern focused on the collective journey during which all mankind should work on the SDGs together (diagonal strips). The contradictions and separation of processes that precede a productive teamwork, were realized as waves that never touch each other, chaotic clashes of color and the beginnings of diagonal strips containing all colors.

The refinements for the last ribbons were based on personal aesthetics and experiences from work in the museum: The dark blue borders next to the biosphere goals seemed to restrict the uncontrollable development of nature and was replaced with the light blue color, representing Clean water and sanitation. Instead of the dark blue weft, white was chosen to emphasize the role of science in achieving sustainable development together.

By weaving just slightly differing ribbons technical problems such as the changing of front and back could finally be mastered.

The main (personal) realizations from weaving the final two ribbons were that the importance and beauty of nature in its uncontrollable, self-sustaining way should be respected and trusted. That includes aspects of nature in every person. At the same time, decisions such as the commitment to peace justice and equality are highly human-centered and characterized by a high level of control. Finally, the connecting importance of partnership and science was again emphasized and made tangible.

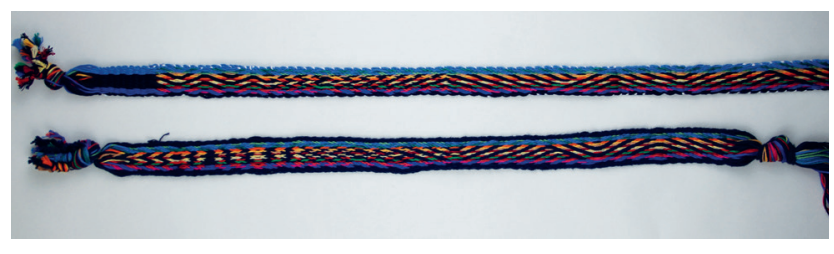

Figure 21: Ribbon No. 9 and No. 10.

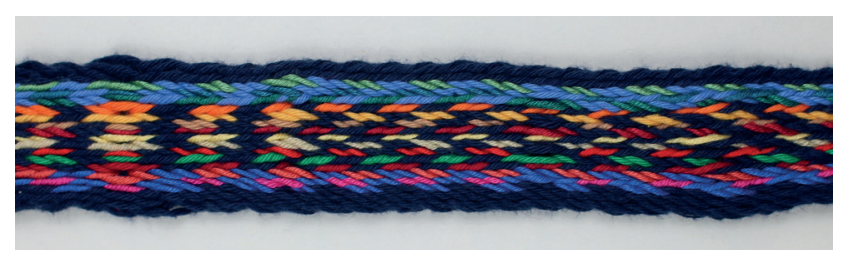

Figure 22: Detail of ribbon No. 9 showing the transformation from divided efforts to reach the SDGs to coming together.

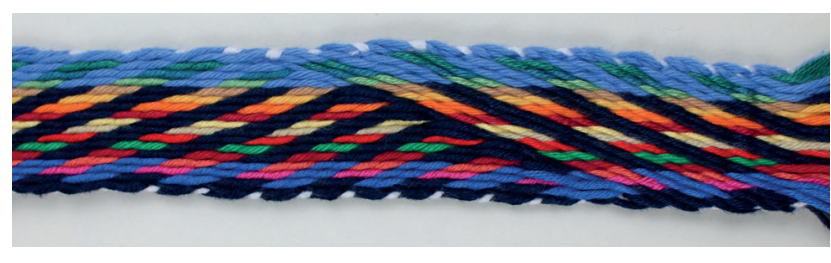

Figure 23: Detail of ribbon No. 10 with colors, representing SDGs being connected and the white weft thread appearing along the edge. 


\section{Conclusion and follow-up}

In practicing SDG weaving, a mode of „external“ thinking was activated that surpassed the mere representation of goals and fostered ideas about handling all 17 goals at the same time. In a playful way, the author went from a point of curiosity in an unusual idea to mastery of an ancient weaving technique that can be easily integrated into every-day life. Be it as a means to reflect on SDGs or as a general support to one's thinking.

In discussions within the team, the effort of learning how to weave was perceived as a hindrance to using tablet weaving in a time-constrained workshop environment. However, the author thinks, that weaving confronts you with the fact that complex tasks cannot and should not be solved with superficial approaches and in haste. Therefore, the slowness and time-consuming aspects of tablet weaving actually proofed to be the strength of the method.

Out of personal curiosity the author produced another ribbon to, some months after the official end of the experiment and thereby transferred the newly acquired cognitive skills to her own field of expertise: textile conservation. In September 2019 she joined a team of handcraft men and restorers, to prepare the original glider by the flight pioneer Otto Lilienthal (1848-1896) for a new permanent exhibition at the Deutsches Museum in Munich. The first steps on the path to an informed conservation decision is always the close examination of the materials and techniques used by the original maker as well as later additions. The glider shows many traces of repair on the textiles, which are characterized by the weave of the fabric, sewing threads, glues and the mode of application. In a month-long process data was collected on each textile in order to differentiate between original vs later addition, to put them in chronological order and to understand the ageing behavior of the material. Based on the information, visualized in a drawing and an excel sheet, the author used her knowledge on tablet weaving to create a pattern, that connected the data and allowed her to process it. In the end the weaving took just about ten minutes, while days were spend to plan the pattern and thereby find the linking elements as well as individual characteristics of each textile. They were then allocated to one tablet weaving card. During the weaving the position of the cards could be changed easily and so it was possible to sort the textiles, they represented, in a chronological order and by material in one ribbon.

This final example showed, that practicing tablet weaving has the potential to handle complex situations and guides the weaver from mere representations of data to real interaction with it. However, the author made the experience that this level of reflection could only be reached, when working with familiar information. Furthermore, Verena Winiwarter and Ellen Harlizius-Klück agreed on the assumption that a predisposition in the field of textiles is needed to achieve this level of cognitive development. It was therefore concluded to follow-up this project with professional weavers, who could contribute their tacit knowledge on a complex textiles technique to linking the SDGs, rather than organizing weaving workshops with SDG stakeholders.

\section{References}

Arnold, Denise Y: “Comparative Reflections on Andean Weaving as Science”, unpubl. Article, 2019.

Clark, Andy and Chalmers, David "The Extended Mind", Analysis 58 (1), 7-19, 1998, https://www. nyu.edu/gsas/dept/philo/courses/concepts/clark. html; accessed on March 28, 2020.

Crockett, Candance "Weben mit Brettchen." Bern, Stuttgart, Wien: Haupt, 1994.

Goslee, Sarah “Tablet Weaving Theory”, Philipa's String Page, 1996-2019, http://www.stringpage. com/tw/twtheory.html; accessed on February 23, 2020 .

Griffiths, Dave "Further Attempts at Untangling Tablet Weaving", The Penelope Project Blog, 11.05.2018, https://penelope.hypotheses.org/674; accessed February 23, 2020.

Harlizius-Klück, Ellen "ERC Consolidator Grant 2015. A Study of weaving as technical mode of existence PENELOPE", unpubl. Annex 1 to the Grant Agreement (Description of the Action) Part B.

Independent Group of Scientists appointed by the Secretary-General "Global Sustainable Development Report 2019: The Future is Now - Science for Achieving Sustainable Development." New York: United Nations, 2019, 
https://sustainabledevelopment.un.org/ content/documents/24797GSDR report 2019. pdf; accessed February 23, 2020.

McLean, Alex "The Twist and Turns of Tablet Weaving", The Penelope Project Blog, Munich 03.06.2019, https://penelope.hypotheses.org/670; accessed on February 23, 2020.

TEEB "TEEB for Agriculture \& Food: Scientific and Economic Foundations", Geneva: UN Environment, 2018, http://teebweb.org/agrifood/ wp-content/uploads/2018/11/Foundations Report Final October.pdf; accessed on February $23,2020$.
United Nations: "Sustainable Development Goals Knowledge Platform”, 2015, https://sustainabledevelopment.un.org/sdgs; accessed on February 23, 2020.

Wollny, Claudia: “Tablets at Work, $2^{\text {nd }}$ rev. ed.", 201, Bad Neuenahr-Ahrweiler, 2019.

Winiwarter, Verena (Ed.) "Umwelt und Gesellschaft. Herausforderung für Wissenschaft und Politik", KIOES Opinions 8, 2018. Vienna: Austrian Academy of Sciences, https://www.oeaw.ac.at/fileadmin/kommissionen/kioes/pdf/Publications/ Opinions/KIOES Opinions 8.pdf; accessed on February 23, 2020.

\title{
Appendix
}

\section{Weaving a new fabric of society. Reflections on the Sustainable Development Goals and the links between them}

\author{
By Verena Winiwarter, August 2019
}

The SDGs are not just yet another set of UN policy goals that will fuel research and deliver above all money for consultants. ${ }^{1}$ A compelling case can be made that they are a departure from the usual in at least three ways. Firstly, they put all countries in the world in ONE pot. They apply to all countries; they are NOT „us“ talking about „them“. Priorities and challenges will be vastly different depending on the country, of course. But at long last, the world is united in an UN goal effort. Secondly, they are the result of a huge consultation process and not the product of a few desk writers and closed meetings. Thirdly, they are encompassing. They seriously try to cover the entire future development of all countries and not just sectoral slices. Yes, this leads to contradictions. But this is the simple, if sad truth about policies: They have to balance different, often contradictory interests. Actually, there are vastly more goals that are connected synergistically, but there are, true, a few difficult contradictions. For me, the contradictions are proof that the goals are not aloof, but situated in reality.

The UN came up with a prime number of SDGs, 17, although No. 17 is more about the process than about any particular goal. Depicting the goals must have been a formidable challenge to the communication department, and in fact, the icon for goal No 10 was changed in January 2018. The guidelines on the use of the logos and other rules fill 68 pages. ${ }^{2}$ A quick browse on the internet shows that the effect of the guidelines is limited. But most users, despite altering their relative sizes, putting them into circles instead of squares, changing their relation to each other (all forbidden), stick to their tiled character: They remain separate, although their interrelation is often acknowledged by arrows or lines, or even networks of criss-crossing connections.

\footnotetext{
1 See the latest report at: https://unstats.un.org/sdgs/report/2019/The-Sustainable-Development-Goals- Report-2019.pdf

2 https://www.un.org/sustainabledevelopment/wp-content/uploads/2019/01/SDG_Guidelines_January_2019.pdf
} 
This separation, while an important prerequisite for the needed specificity of policy measures, could, and indeed, should be complemented by an equally strong message communicating their inseparability. The ring logo of the SDGs, still set apart in segments separated by white, does not convey this message.

I suggest to turn to one of the oldest techniques of humankind, weaving, to allow another narrative of the SDGs than that coming with tiles and rings of segments. I suggest to tell the story of the SDGs as that of a fabric, a weave, as that of separate, yet inextricably linked strands of society and nature. Such a fabric allows potent metaphors: Each thread on a weave is of equal importance. If one thread is pulled, holes ensue. If they are not properly linked, there will not be a weave, but rather a chaotic and loosely tied mess. I suggest to take the SDG structure as a guideline to the weaver: 16 goals are the warp, goal 17 , "partnerships for the goals" is the weft. The biospheric goals and the blue-green hues, complemented with the browns and yellows and reds of other goals make for a colourful new weave of society. It is also quite clear that many different patterns can and should be woven.

Network analysis shows that the goals No 10 and 12 are central, meaning that sustainable consumption and production and the curbing of inequality are the best way to reach other goals. This could be reflected in the patterns.
The so-called wedding cake diagram, another way of thinking through the goals' relationship, shows that the biosphere-oriented goals (13, 14, 15 and 6) form the basis of all sustainable development - again this is a message to be transported in the weave pattern.

Yet another weave could arise from a meta-level analysis of the relations between the goals, showing how many goals are linked in a synergetic way but also pointing at the trade-offs. All such patterns can be based on already existing scientific analysis. ${ }^{3}$

While any such artistic implementation is of high value in its own right, and while the idea of a new weave of society needs to be made tangible in objects, there is also an important practice aspect: Actual weaving as a shared group activity, embedding the results into an actual fabric, e.g. as armbands or as bookmarks, to name but the simplest products, provides as a community strengthening activity and would bring a much-needed practical component to seminars. It would be transformative in the sense that not only cognitive, but also manual skills and the design thinking of weavers would become recognized through experience as essential for the SDGs.

For all these reasons, „weaving a new fabric of society" could be developed as a transdisciplinary endeavour and an important contribution to the sustainability debate. 


\section{Documentation of reflections and feelings about the first attempts in tablet weaving}

By Charlotte Holzer, August 2019

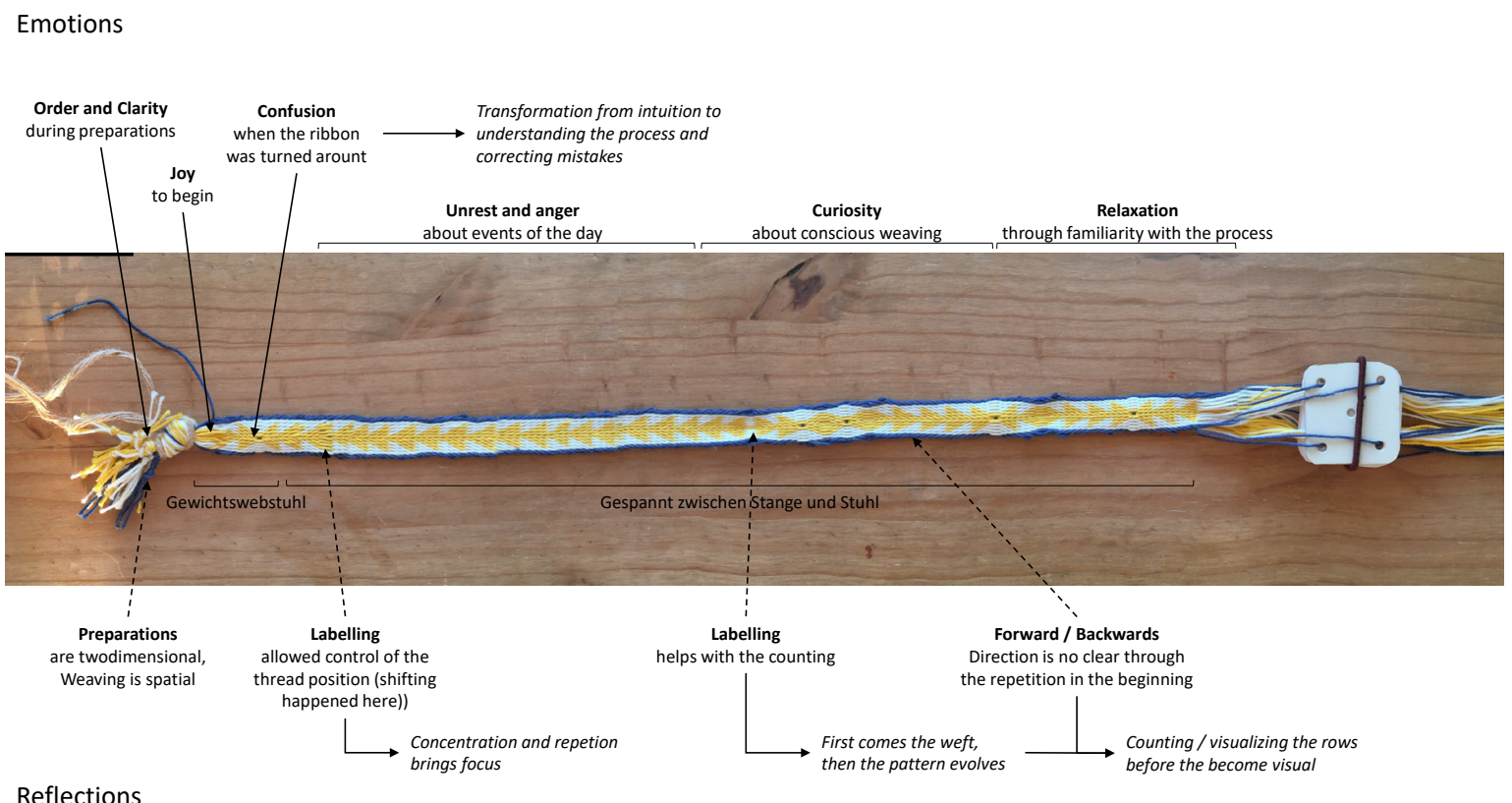




\title{
Crafting Sustainability: On weaving as mode of (re-)production
}

\author{
Ellen Harlizius-KLÜCK
}

\section{Introduction}

In this issue of KIÖS Opinions, three voices carry three perspectives of looking at weaving into the discussion of the seventeen goals for sustainable development (at least this is how I think the term Sustainable Development Goals is to be understood, actually indicating that they are about development less than about sustainability). One voice (Verena Winiwarter) is looking for a better way to represent the complexity of the task ahead, a better way to handle the series of goals that are supposed to lead to a sustainable society. A second voice (Charlotte Holzer) tries to make accessible the rationale of tablet weaving as a means to practice (the representation of) complexity, trying to translate it into a how-to, step-by-step introduction to gain insight into the trade-offs and mutual dependencies of the SDGs. Now comes a third voice (Ellen Harlizius-Klück), claiming that weaving is a sustainable mode of existence (at least in its so-called pre-industrial form), however incommensurable for someone using the yardstick of a knowledge that achieves goals directly and with a measurable trajectory of success. This claim results from the investigations carried out in the 5-year research project „PENELOPE: A Study of Weaving as Technical Mode of Existence“, funded by an ERC-Consolidator Grant of the European Commission. ${ }^{1}$ This project will be introduced in the following paragraph. The aim pursued by the three of us from our respective starting points was to test the feasibility of Verena Winiwarter's idea to teach stakeholders and politicians concerned with SDG goals some of the principles of weaving as a sustainable production mode.

\section{The PENELOPE Project}

The PENELOPE project builds upon the hypothesis that there was a significant but tacit contribution of textile technology to the advent of science in ancient Greece. However, this contribution was overshadowed by (1) a concept of rationalism that favoured a hylemorphic view on production and reproduction (Aristotle, Metaphysics Book 6), and (2) a distinction of proper and metaphorical meaning (Aristotle, Poetics 1457b.7, Rhetorics 1410b.13) as well as (3) a number concept that builds upon a unit progressing into the infinite (and not on forms and shapes of numbers like in the Pythagorean approach, cf. Aristotle Metaphysics M6 1080b16, M8 1083b8). The aim of the PENELOPE project is to explicate ancient Greek weaving and other traditional ways to weave as a paradigm for social and natural order: Woven fabrics were a materialized cosmology, not only in its state of being, but also in its process of becoming.

The results from the investigation of weaving in archaic Greece, but also from handloom weaving in India or the highly complex weaving in the Andes show that, although weavers do not talk about the underlying principles of their work, this order still transfers into other domains in their respective society. It is not simply the manner of ups and downs of threads that is transferred, but the whole idea of weaving complexity: the balance, the patterned or-

1 The PENELOPE project receives funding within the HORIZON 2020 EU Research and Innovation programme under Grant No. 682711. 
der, the rhythm, the idea of bonding, the mixture without mixture (poikilos: a patterned cosmic order to which each element contributes without giving up or losing its properties). This is what the PENELOPE team addresses as (technical) mode of existence of weaving. It is a technical mode in the ancient sense where techné is an art, a craft, a knowledge of genesis - not only of human-made things but also of natural growth.

\section{Weaving as technical mode}

The narrative of the development of textile technology nowadays is strongly intertwined with the narrative of industrialization, so strongly, that it takes an enormous effort to raise even the slightest interest of looking into that question again: What is weaving? What does the weaver know when s/he knows how to weave? The common assumption is that this knowledge is materialized in our machines, formalized in our drafts. Is that all a master weaver needs to know? How then is it possible that weaving could once (and still does in some communities) describe the order of the cosmos? That it helped to understand and sustain societies? In a dialogue much less famous than the Republic, Plato presents the Statesman as weaver (Plato, Statesman). In an investigation ceaselessly searching for the type of knowledge that makes up a good ruler, weaving knowledge becomes the subject of a conversation that starts as if it were about rationalizing the statesman's knowledge as a type of arithmetic, but then turns to the art of intertwining warp and weft. This turn from „pure“ to „applied“ knowledge has been explained as due to Plato coming of age. Moreover, so is Socrates, he is not even speaking in the dialogue but only listening to a conversation in which a young namesake, Socrates, is answering to the questions that will in the end determine the knowledge of the Statesman. Age, as this seems to imply, does not make us wiser, but lets us abandon the straight path of rationality in favor of the myths and metaphors of weaving.

Explanations and rationalizations like this are what the PENELOPE project tries to make visible as violation of the principle of epistemic justice. The example of the reception of the Platonic dialogue is not important because it blames age for abandoning reason, but because it blames weaving for being something unreasonable, irrational - this is what establishes the judgement of insaneness in the first place. Moreover, Plato seems to confirm: „Of course no man of sense would wish to pursue the discussion of weaving for its own sake“ (Statesman 285d). „No one in his right mind would ever consider weaving for its own sake." (Statesman 285d) But beware Platonic irony!

\section{Trying to speak well about weaving}

In the PENELOPE project, we frequently discuss the issue of epistemic justice, formulated by Bruno Latour as „speaking well“ about values that are important to people. Studying the literature in combination with a deep involvement into the practice of weaving allowed us to gain insights that enable us to speak well about what concerns the weaver. Three such insights merit particular mention.

- As soon as concepts of science, such as number, or measure, or code, or representation are employed (to make weaving understandable to scientists), a series of misunderstandings is set on track. These are (1) that one only needs to apply the code or draft, (2) that weaving is just about crossing warp and weft, (3) that weaving is just matrix multiplication, (4) that patterning a fabric is about employing geometrical symmetries, and (5) that you can determine mathematically if a fabric does or does not hang together.

- As long as we do not use concepts established by science no one will take our talk serious (see Plato's dialogue on the weaving statesman). We sidestep such an approach consciously, in order to avoid applying measurement that would be incommensurable to the weaver's way to know and speak. Unfortunately, this silences us.

- As soon as we give a moment, an instance of practice, albeit sketchy or diagrammatical, to the reader, we face the difficulty that this is taken for the whole of weaving.

Finding a way to speak well of weavers to non-weavers is fraught with difficulty. In the following I nevertheless try to find a way to speak of the process of weaving as it might be beneficial for the context of the sustainable development goals. 


\section{The Binary Micro-Decisions}

Weaving is a technology of stunning simplicity. All the weaver needs to do is to cross the weft along the warp by either going over or under it. Where then, is the knowledge?

All the computer needs to do is to run through a series of instances of storage units that either have currency (1) or not (0). Is what computers do thus of stunning simplicity? Oh no, one would say. This is only the most basic definition. You will never understand what a computer is able to do when you take this idea of a "bit" as the whole of digital technology. It can become extremely complex by following a series of combinations and even reach human intelligence at ever-increasing levels.

Well, the same goes for weaving. You will never be able to understand what a weaver is able to do when you take the idea of crossing two threads as the whole of weaving technology. Still, this is exactly what people usually do.

In a contribution to a collection of papers on $\mathrm{Mi}$ croperformativity, we, the PENELOPE team, began to replace the problematic terms "tacit" knowledge, „practical“ knowledge, or „embodied“ knowledge by describing it as micro-performative. Although this does not solve the difficulty of achieving a clear explanation of the specificity of weaving, it draws the attention to a different category, namely to making decisions by habits that go mainly unawares, but sometimes pop up to awareness (in the right moment or kairos). It is a rhythm similar to music or dance, which helps to smoothen the decisions and makes weaving fast. This part looks like a mechanical movement from the outside. However, it is not just rhythmic but rather algorithmic and thus includes bifurcations, case-sensitive decisions of a higher level at certain points in time and process.

Micro-decisions with long term and wide-ranging macro-consequences, this seems to be what the weaver is aware of without being able to follow the whole course from the single fibers twisted to a thread, along the filiation of beings and the networks of societies, up to the web of stars and planets, in steps that a non-weaver could not easily follow. Still some philosophers and poets took that path and expressed it in their work. As detailed above, Plato explains the true knowledge of the Statesman with the para- digm of weaving (Politikos 311c). In addition, Philo of Alexandria calls the universe a wonderful weave and therefore the inventor of weaving a scientist (Peri tou oneirous I, $\$ \$ 203 \mathrm{ff}$ ). Pherecydes of Syros, one of the first prose writers in history, describes in detail the preparation, performance, and ritual completion of the marriage of Zas and Chtoniê, two deities preexisting the world as we know it. At the third day of the wedding, „Zas makes a robe, great and beautiful, and in it he patterns (poikillei) Earth, Ogênos, and the dwellings of Ogênos", the last indicating the signs of the Zodiac. (Clemens of Alexandria Stromata VI 9.4.) Other sources, although from second hand, also know about this cosmic garment.

\section{The Chain of Micro-decisions}

But what in the process of weaving makes it able to serve as a paradigm for cosmic order? And what makes it able to serve as a best practice example for sustainable behavior? Both results are never established as a goal of that process.

The weaver does not apply a pre-established design to a specified material by means of tools such as loom and shuttle. Still, this might be a short description of what an automatic loom is doing, although this description leaves out all technical details. Instead, the master weaver establishes a complex and well balanced fabric by making a series of binary microdecisions that shift up to an overall design, texture, and form. Weavers, after years of practice, are able to oversee what follows from such micro-decisions for the whole of the fabric. Such decisions are not only constrained by and to the point where a weft thread needs to cross a warp thread either over- or underneath.

Similar chains of decisions, albeit not visible in the working process, concern the choice of yarn, its twist with regard to strength, as well as direction, its type, its thickness, its color and the fastness of the color, thus the question of proper dyeing, of proper use of mordant, of the choice of raw material, of the crops that deliver such material, where they need to be planted, under which climatic conditions, etc.

A third chain of references concerns the social relations involved in the work of the weaver, the question who spins the yarn, who pays for the product, the question if the outcome (not necessarily money) will 
be sufficient to allow him to take care of his children and the parents when they come of age. All weaver collectives developed a sustainable way not only of living and caring for their raw material and the environment it requires, but also for the people along the chain of production (I dislike the term chaîne operatoire) and reproduction of that whole system including humans, plants, animals, food, clothing etc.

Following the reasoning of modernization, the idea that clothes should be cheap and not take long to produce, the idea that the more we produce, the higher the demand and the cheaper the product; on top of paying people just for their time of work and not covering the expenses for reproduction (food and education for children, money for life after work), weavers who leave their rural communities in India and work in the textile factories of the crowded towns not only lose their family contacts. They dry out the fertile system that they will need when they come of age, or need to fall back upon in times of crisis. The millions of workers heading back to their villages when the factories closed down due to the spread of COVID- $19^{2}$ are a case in point. Their arguably backward weaver colleagues in the rural areas, due to their domestic type of production, could simply go on almost as usual in their perfectly equipped home-office. ${ }^{3}$ I see this as a strong indication that pre-industrial modes of work could well become post-industrial ones.

The technicians and weaving company owners, along with a large part of the public of the Global North believe that they copied the weavers' knowledge into their machines. Thus, we infer with respect to the weavers that there is only manual labor left to do. However, all the precious knowledge and skills that weaving provides for understanding complex structures, limits and supply of resources, organizing communities, balancing relations, is still to uncover and in danger to get lost.

Following the reasoning of industrialization, Global Northerners lost the understanding of micro-decisions and their consequences. The industrialized world thinks in causalities and wants to speak straight. We, grown up in such a society, make plans to solve pro- blems. We set goals and measure how close we get to them. We hate digressions and detours. Especially as we have no time. When we think it is a good idea to consume less meat in order to change the food industry, we become vegan fundamentalists, buying vegan shoes and handbags - heading into the next malign inversion, as vegan leather is still mainly made from polyurethane or polyester. A path to a sustainable development might not be of the kind imagined in the SDG squares. It might be a long and winding thread used in chains of micro-decisions by people who have learned the craft of sustainable development. But how could such a craft-based approach work? The following chapter outlines that there might not be a shortcut, but that a crafts-based approach needs another kind of learning altogether.

\section{A weaving workshop?}

It seems all-too-evident that to teach the sustainability lesson that can be gained from weaving, one needs to teach weaving to those in charge of sustainable development, e.g. politicians. However, there is a danger of devaluing skilled weavers' knowledge by launching short workshops pretending to teach weaving when they only present well-prepared examples excluding all the tedious preparatory tasks where sustainable conduct is actually crucial. The examples of the Andean or Indian communities are striking, but especially as weaving is bound to the landscape and its people, as the materials are taken from the plants that grow there because of the best conditions, why should that approach be transformable to the situation of the typical cosmopolitan way of life of the Global Northerners today? A way of life wearing clothes from plants grown in Kazakhstan, woven in Bangladesh, sewn in India, and consumed in Europe by people eating meat from Argentina, drinking water from France and driving cars from Germany? Are we not cherry-picking when we take weaving out of the limiting context which makes up its character in the respective communities? Is it not preposterous

2 https://penelope.hypotheses.org/2100

3 Indian handloom weavers are well equipped with mobile phones and sometimes computers. They know how to use digital technology for testing designs or calculating them anew when they want to make changes that were not yet transformed, by habit or practice, into a part of their tacit repertoire. See Mamidipudi and Bijker 2018. 
claiming to be able to take part in their knowledge by weaving some ribbons in SDG colors?

One cannot take weaving apart into elements that can be recombined and still yield the same knowledge as before. For a short-term workshop to actually be true to the essence of weaving, we would need to prepare items that do not suggest a simplicity contradictory to the complexity of weaving, and therefore would support the wrong idea.

We would need to de-familiarize the thinking first and then it is possible to see the concept of weaving. The level where I begin to understand the weaving way of composition and construction is not comfortable to the brain as it has to deal with a huge complexity of information and conditions to respect and relate. This state is a necessary threshold for weavers to pass, and probably the bifurcation after which some leave weaving and others feel challenged to dig deeper into the technique. However, it is not possible to achieve this transforming phase in a well-prepared weaving session of one day or two. The „change of mind" arguably connected to weaving (or other crafts) seems indeed to be what silences weavers, what makes their knowledge tacit. It is not the practical status as such, it is the development of a complex way of thinking that defies language.

As Charlotte Holzer's experiment shows, a successful procedure like that is not easy to achieve. She is a trained textile conservator and our idea provided her with a new instrument of thinking through her data. In fact, her work is a wonderful demonstration that Verena Winiwarter's idea can work. However, this is not transferrable into a tablet-weaving course for politicians.

\section{A workshop with Weavers?}

Would it be possible to keep up such a way of speaking well about weaving during a short-term workshop introducing weaving practices to politicians or other stakeholders of SDGs? We had our doubts. True, it is possible to set up a warp in advance, to prepare the colors and cards in order to spare the workshop participant the frustration of that tedious work. However, then we deprive the process of a huge amount of decisions crucial to the result and the knowledge we would like to convey.

Would it help to do that experiment with weavers? Shall our team present the idea to them and see if they can make sense of it? This will indeed be our next step: to establish a kind of laboratory entitled „looms-in-motion“ where we invite weavers from China, Laos, India, Germany and Austria to bring their looms and practice side by side. The looms will be very different in construction, the practices will also be very different and the weavers might not share a common language. Our team is currently investigating way of including SDG concerns into this laboratory.

\section{Conclusion}

Weaving is a complex bidirectional craft. The production process of inserting a weft thread goes from right to left and back again repeatedly. The work progresses in form of a zigzag movement, establishing designs indirectly by adding up thread by thread in interfering arrangements. In the case of tablet-weaving, the weft is even invisible (see Charlotte Holzer's explanations in this issue), so what does it contribute to the design at all? Weaving rejects our aim for fast or at least comprehensible progress, establishing a form following a preconceived outline. By looking longer at the movements of tablet weaving, we might at some point be able to understand that the design comes from the entanglement of the warp threads of different colors that sometimes hide behind and sometimes come to the fore, arrested by that invisible weft to which we, mistakenly, fixed our eyes in the beginning. In weaving, almost everything is indirect, deflected. It consists of micro-movements, changes, decisions that do not yield results immediately. Decisions on tablet-turns only show their consequence some turns later, which also applies to errors. It is this fact that can drive beginners mad. But is this not exactly the situation we have to face in pursuing a sustainable society? To understand entanglements? To be prepared for zigzag movements? And to value microdecisions which might show their effects only later? Will our society be able to weave the seventeen goals together despite such discouraging circumstances? 


\section{References}

Aristotle, Rhetoric, Aristotle in 23 Volumes, Vol. 22, translated by J. H. Freese. Cambridge and London: Harvard University Press; William Heinemann Ltd. 1926.

Aristotle, Poetics, Aristotle in 23 Volumes, Vol. 23, translated by W.H. Fyfe. Cambridge, MA: Harvard University Press; London, William Heinemann Ltd. 1932.

Aristotle, Metaphysics, Aristotle in 23 Volumes, Vols. 17, 18, translated by Hugh Tredennick. Cambridge, MA: Harvard University Press London: William Heinemann Ltd. 1933, 1989.

Harlizius-Klück, Ellen "Weberei als episteme und die Genese der deduktiven Mathematik. In vier Umschweifen entwickelt aus Platons Dialog Politikos". Oldenburg Universität: Dissertation, 2004.

Harlizius-Klück, E. “The Importance of Beginnings: gender and reproduction in mathematics and weaving." In M. Harlow and M.-L. Nosch (eds) Greek and Roman Textiles and Dress. An Interdisciplinary Anthology. Oxford \& Philadelphia: Oxbow, 46-59, 2014.

Latour, Bruno "An Inquiry into Modes of Existence. An Anthropology of the Moderns". Cambridge: Harvard University Press, 2013.

Mamidipudi, A., and W. Bijker "Innovation in Indian Handloom Weaving." Technology and Culture 59, no. 3, 509-545, 2018.

Philo of Alexandria, Peri tou oneirous, http://www. earlyjewishwritings.com/text/philo/book21.html

Plato. Plato in Twelve Volumes, Vol. 12 translated by Harold N. Fowler. Cambridge, MA: Harvard University Press; London: William Heinemann Ltd. 1921. 
Biographies of the authors 


\section{Biographies of the authors}

Ellen Harlizius-Klück - Since childhood, I am fascinated by the logical structure of textiles and the possibilities of engaging this logic and mathematics for their production. Educated in a school for girls that traditionally included courses on all types of textile techniques, but only provided a low level grade, I later did my exam at a secondary school, formerly only for boys and with a focus on natural sciences education and with no practical courses. These contrasts come along with me ever since.

It was the year 1977 when I finished my secondary school exam and went to university. Well aware that the integration of my two main interests: art/textiles and mathematics could not go hand in hand with the curriculum at universities, I took the rare chance of studying at a "Gesamthochschule", a high school type established in the state of North Rhine-Westphalia. There, I did my teacher exams in mathematics and arts. Later these high schools were transformed into Universities, and today, such combinations are no longer possible.

Along a break for child care, I started to work as artist, with textiles and their structure being my favorite material and topic. My art quilts were presented at exhibitions in Europe, Japan and the USA. However, I also encountered a lot of resentments among my closer art colleagues who claimed that this is just a housewife's hobby.

Artist work always includes an intellectual examination of material and idea, usually not in the form of writing. However, I started writing down my arguments about women's artwork and especially textile art, and also studying philosophy at the University of Düsseldorf. For a long time, my two professions as artist and author went well hand in hand, culminating in a series of works ranging from huge textile installations to small book art or art books, and multiples where textile and text were integrated.

In the year 2002, I was appointed professor for Textile Studies at the University of Osnabrück where I was, again, confronted with resentments of colleagues against such a minor topic that should not be part of a University at all. Notwithstanding such low estimation, which is common in the sciences, I did my $\mathrm{PhD}$ on "Weaving as episteme and the development of deductive mathematics". Although the "and" in the title looks like an innocuous combination, demonstrating a connection of weaving and the advent of science in early Greek mathematics was exactly what I was about to do.

This PhD marked the beginning of my scientific journey to the present project. In 2006, I was scholar-in-Residence at Deutsches Museum, investigating the earliest printed weaver books and manuscripts. When the Museum of Plaster Casts of Classical Sculptures Munich presented a Penelope exhibition in the same year, I was provided a warp-weighted loom and began to study ancient weaving practically. In 2009, I set up a laboratory with warp-weighted loom, library and computer desk as part of an exhibition of ancient textiles (Clothiers Museum Bramsche). For nine months, I worked there, oscillating between computer and loom, and investigating the possibilities of the latter. These studies of ancient textile technology provided a deeper understanding of the intellectual role that weaving, as a practice of ordering elements according to

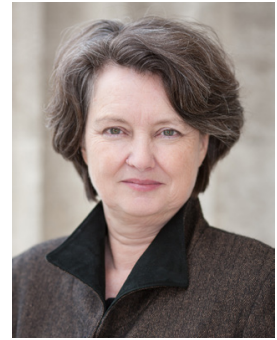


rules, played across domains like poetry, music, dance, mathematics, and even ideas of political organization in archaic times. In the years 2012 and 2014, a Marie Curie-Grant enabled me to do research at the Centre for Textile Studies (CTR) of Copenhagen University, followed by a grant for collaboration between Danish and German textile researchers, issued by the Humboldt Foundation (Anneliese Mayer Award for Marie-Louise Nosch, head of CTR). In 2015, I received an ERC Consolidator Grant for the project PENELOPE: A Study of Weaving as Technical Mode of Existence, which is conducted at the Research Institute for the History of Technology and Science of Deutsches Museum Munich. e.harlizius-klueck@deutsches-museum.de

Charlotte Holzer - In my work as a textile conservator and researcher, I enjoy to experiment with the joints that connect every single bit of contextual information on an object and my choices for the treatment. In my early days as an university student or during my internships in museums, supervisors helped me to bridge the gap that separates knowledge from action. They thereby saved me from getting lost in the most wonderful stories about Buddhist thangkas or forgetting time over a textile analysis of Baroque silk fabrics or trying yet another instrumental method to identify asbestos. However, the influence of conservators from various backgrounds showed me that already the steps of examination and research produce countless variables affecting the decisions in the conservation process; not to mention the numerous approaches to the actual intervention on the artefact. While I focused on learning the conscious and often unconscious decision paths of a conservator during my education, I aimed at understanding the various possible connections during my PhD. By then, it was high time, that I found my own way, questioned it, tried something new and finished it. So it was no surprise, that when Ellen Harlizius-Klück approached me with Verena Winiwarter's project proposal on weaving the SDGs that the idea immediately struck my core research and learning interests.

Ever since my days at school, this inner core of mine refuses to specialize in one field. Of course, the sheer amount of knowledge makes it impossible to attain the status of an universal scholar today, but the profession of the conservator at least offers the possibility to work very interdisciplinarily. I started my five-year study program at the University of Applied Arts Vienna in 2007 and dived right into this very special mixture of natural science, the arts, documentation and practical work on historic objects. I had the unique opportunity to join a team of conservators working on the collection of a Buddhist temple together with local monks and inhabitants of the Himalayan village Nako, India. I spent my mid-study internship at the Organic Artefacts Conservation Studio of The British Museum London, which not only opened a new world to me in terms of technical skills, but also regarding the vast variety of human forms of expressions in handcraft worldwide. My final thesis was dedicated to the scientific study and conservation of an asbestos proximity suit from the Technisches Museum Wien - a project that was accompanied with many emotions. In 2012, I went on to work at the Textile Conservation Studio of the Bavarian Nationalmuseum in Munich for two years. During this time, I took a break from academia and immersed myself into the pool of experience on historic costumes, accessories and tapestries shared by the team of textile conservators. 
In 2014, these colleagues drew my attention to the glass fiber dress of Infanta Eulalia at the Deutsches Museum. I started research on the dress and comparable textiles within the PhD program of the Technical University of Munich. The project was situated at the Deutsches Museum, but for my comparative study on glass fiber textiles, I visited collections in Europe and North America. I also received the Rakow Grant for Glass Research 2016 from the Corning Museum of Glass and developed a methodology for cleaning historic glass fibers in their conservation laboratory. Every time I came back to Munich after my travels, I was glad to be back at my home base, but I also felt so much enriched by everything I had seen and the experience people shared so generously with me.

After having spent seven years with arts and craft textiles, I switched back to the fascinating world of technical textiles. Beginning with a research project on the Russian Space Suit Sokol KV-2 from the Deutsches Museum and then moving on to my current position as a project conservator for the marine navigation, aviation and space collection. My main tasks are to ensure a safe environment for the objects in the new exhibitions and to carry out treatment on textiles, like the original glider of Otto Lilienthal from 1894. This project allows me not only the refine and widen my personal research and conservation skills, but also to plan and execute the measures in a team of handcraft people, restorers, historians, architects, technicians and exhibition designers.

To sum up my research interests, I believe that a holistic approach is the ideal base for informed treatment choices. It can best be realized by opening the doors between the different aspects of a conservator's work, but also to other disciplines. Constraints, such as time and financial limits, lack of equipment or experts for advice, might hinder retrieving data, but the decision to connect the information available lies with the conservator. - c.holzer@deutsches-museum.de

Verena Winiwarter - I was fascinated by chemistry from an early day on. After graduating from a secondary school, (Realgymnasium mit Darstellender Geometrie) I went to a technical college, where I got a 4-semester engineering education. In my first employment, at Vienna University of Technology's department for analytical chemistry in the research group for environmental analytics, I was given the possibility to work in research contexts. The analysis of acid rain, airborne dust from industrial emissions and nutrient flows into water, as well as the analysis of fogs and glaciers made me aware of the seriousness of environmental pollution. In 1986 we would have liked to analyze precipitation in the aftermath of the Chernobyl disaster and I realized then that the ability to measure pollution is limited by more than just analytical constraints. We simply did not have the necessary equipment. I enrolled at Vienna University and studied history and communication sciences. Due to a fantastic teacher, Karl Brunner, I got into medieval history, graduating with a study on the reception of agricultural literature from Ancient Rome in the Early Middle Ages. I asked what to me seemed a straightforward question: under the different conditions with regard to climate and soils, were these agricultural manuals of practical use in the centers of the early medieval period? During the work on this master thesis I first got in contact with environmental history, which, I found out, did ask such questions. 
In the late 1990s, I helped build a European Society for Environmental History after having participated in a conference of the American Society; my Habilitation at University of Vienna's Department of Anthropology (2003) was an attempt to find an institutional home for my research interest under the umbrella of Human Ecology, but eventually, the Interuniversity Institute for Interdisciplinary Research (IFF), later turned into a faculty of the Alpen-Adria-Universität Klagenfurt proved the right home base for the kind of environmental history me and my colleagues had started to do: Work that crosses disciplinary boundaries with regard to data and concepts. Eventually I was elected as Austria's first professor of Environmental History, at the Institute of Social Ecology of the IFF; since 2018, the Institute has found a new home at the University of Natural Resources and Life Sciences in Vienna. I chair a network initiative there, the Centre for Environmental History since 2003. The Science Journalist Association of Austria elected me as "Scientist of the Year" in 2013, and a year later, my award-winning popular environmental history, co-written with Hans-Rudolf Bork came out.

The interaction between society and nature, with a focus on side-effects became my field. Following on my early agricultural work, I dug into the history of the knowledge about soils, which is part of the story of the (un-)sustainability of preindustrial agriculture. After two large grant-based projects on the history of the Danube and its tributaries in the area of Vienna, I have embarked on a journey that brought me back to my chemistry beginnings: The history of toxic, insidious legacies which often stem from mining or weapon's production. This work has taught me that disarmament and peace are a prerequisite for sustainable development, and vice versa, sustainability is a prerequisite for peace. Environmental history to me is historical sustainability research.

It was a great honor to be elected as a full member of the Austrian Academy of Sciences in 2016, where I chair the Commission for Interdisciplinary Ecological Studies. When the Sustainable Development Goals we made public in 2015, the commission started to discuss what members could contribute. This resulted not only in a report published in 2018, a conference at the Academy with more than 300 participants, but also in my questioning the goals' depiction as single entities. This would eventually lead to the co-operation with Ellen HarliziusKlück and Charlotte Holzer. To prepare for the project, I taught myself the basics of tablet weaving, but otherwise, my handicraft skills are limited to knitting and all kinds of work with (waste) paper and glue. I consider myself a tinkerer. verena.winiwarter@boku.ac.at 


